Review article

\title{
The neural basis of effort valuation: A meta-analysis of functional magnetic resonance imaging studies
}

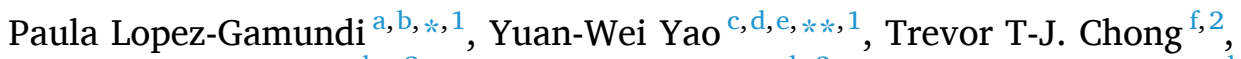 \\ Hauke R. Heekeren $^{\text {c, d,e, }}{ }^{\text {, }}$, Ernest Mas-Herrero ${ }^{\text {a,b,2 }}$, Josep Marco-Pallarés a,b, 2 \\ ${ }^{a}$ Department of Cognition, Development and Educational Psychology, Institute of Neurosciences, University of Barcelona, Passeig de la Vall d'Hebron, 171 , 08035 \\ Barcelona, Spain \\ ${ }^{\mathrm{b}}$ Cognition and Brain Plasticity Unit, Bellvitge Biomedical Research Institute (IDIBELL), C/ Feixa Llarga, s/n - Pavelló de Govern - Edifici Modular, 08907 Hospitalet de \\ Llobregat, Spain \\ ${ }^{\mathrm{c}}$ Department of Education and Psychology, Freie Universität Berlin, Berlin, 14159, Germany \\ d Einstein Center for Neurosciences Berlin, Charité - Universitätsmedizin Berlin, 10117, Germany \\ ${ }^{\mathrm{e}}$ Berlin School of Mind and Brain, Humboldt-Universität zu Berlin, Berlin, 10117, Germany \\ ${ }^{\mathrm{f}}$ Turner Institute for Brain and Mental Health, Monash University, Victoria, 3800, Australia
}

\section{A R T I C L E I N F O}

\section{Keywords:}

Effort

Subjective value

Effort-based decision making

Value integration

fMRI

Ventromedial prefrontal cortex

Supplementary motor area

Meta-analysis

\begin{abstract}
A B S T R A C T
Choosing how much effort to expend is critical for everyday decisions. While several neuroimaging studies have examined effort-based decision-making, results have been highly heterogeneous, leaving unclear which brain regions process effort-related costs and integrate them with rewards. We conducted two meta-analyses of functional magnetic resonance imaging data to examine consistent neural correlates of effort demands (23 studies, 15 maps, 549 participants) and net value (15 studies, 11 maps, 428 participants). The pre-supplementary motor area (pre-SMA) scaled positively with pure effort demand, whereas the ventromedial prefrontal cortex (vmPFC) showed the opposite effect. Moreover, regions that have been previously implicated in value integration in other cost domains, such as the vmPFC and ventral striatum, were consistently involved in signaling net value. The opposite response patterns of the pre-SMA and vmPFC imply that they are differentially involved in the representation of effort costs and value integration. These findings provide conclusive evidence that the vmPFC is a central node for net value computation and reveal potential brain targets to treat motivation-related disorders.
\end{abstract}

\section{Introduction}

Every day, we are faced with choices about whether to invest effort to attain certain goals (Bailey et al., 2016; Salamone et al., 2009). These effort demands are often regarded as costly, such that individuals tend to avoid one action if it requires too much effort with respect to the reward it entails (Kool et al., 2010; Kurniawan et al., 2011, 2010; Lopez-Gamundi and Wardle, 2018; Salamone et al., 2018). The ability to accurately weigh energy requirements against potential benefits (e.g., "effort-based decision-making"), is therefore crucial for optimal goal-directed action, and alterations in this function are believed to be a core component of motivational disorders, such as apathy (Chong and
Husain, 2016; Hartmann et al., 2015; Husain and Roiser, 2018), and have been found across a variety of psychopathologies, including depression (Treadway et al., 2012; Yang et al., 2014), schizophrenia (Barch et al., 2014; Park et al., 2017), Parkinson's disease (Chong, 2018; den Brok et al., 2015; Le Heron et al., 2018), and substance dependence (Grodin et al., 2016). Due to its clear clinical importance, there has been a recent surge of interest in how effort devalues prospective rewards, and such studies have demonstrated that effort might be a unique cost, distinct from other more investigated cost domains, such as risk and delay. However, work on the neural mechanisms underlying effort-based valuation have yielded heterogeneous results, and the question of how humans integrate effort and reward remains a subject of

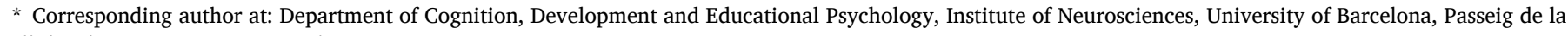
Vall d'Hebron, 171, 08035 Barcelona, Spain.

** Corresponding author at: Department of Education and Psychology, Freie Universität Berlin, Berlin, 14159, Germany.

E-mail addresses: plopezgamundi@ub.edu (P. Lopez-Gamundi), yywyao@gmail.com (Y.-W. Yao).

1 These authors shared first authorship.

2 These authors contributed equally to this work. 
contention.

Most behavioral economic theories of reward-related behavior rely on the assumption that an organism weighs a reward and its associated costs to generate a net value of an option (Kahneman and Tversky, 1979; Sutton and Barto, 1998; Von Neumann and Morgenstern, 1990). A popular hypothesis proposes that, to effectively compare different options, the net value of each must be represented in a 'common currency' (Padoa-Schioppa, 2011; Rangel et al., 2008; Westbrook and Braver, 2015). A network of regions, including the ventromedial prefrontal cortex (vmPFC; and adjacent orbitofrontal cortex) and ventral striatum (VS), have been repeatedly implicated in the encoding of the net value of rewards discounted by the costs associated with obtaining them (Bartra et al., 2013; Levy and Glimcher, 2012). Based on these data, this valuation network is posited to be 'domain-general', as it tracks net value representations regardless of the nature of the reward (e.g., primary vs secondary) (Bartra et al., 2013; Sescousse et al., 2013) or of the type of cost (e.g., risk vs delay) (Kable and Glimcher, 2007; Peters and Büchel, 2009; Prévost et al., 2010).

However, much of these data have focused on outcome-related costs such as risk or delay. Notably, research on effort-based valuation suggests a limited role for the vmPFC and VS for value integration. Instead, other frontal regions beyond this core valuation network, including the anterior cingulate cortex (ACC), supplementary motor area (SMA), and anterior insula (AI), have been shown to signal net value discounted by effort costs (Arulpragasam et al., 2018; Camille et al., 2011; Chong et al., 2017; Klein-Flügge et al., 2016; Massar et al., 2015; Skvortsova et al., 2014; Walton et al., 2003). These findings are consistent with animal studies showing that lesions to the ACC, but not the nucleus accumbens, prelimbic/infralimbic cortex (homologous to the vmPFC), or orbitofrontal cortex, reduce the amount of effort rats invested for rewards (Rudebeck et al., 2006; Walton et al., 2009, 2003). Furthermore, neural activity in the ACC, as measured by single unit recordings, varies with cost-benefit weighting (Hillman and Bilkey, 2012, 2010) and effort-related choice (Cowen et al., 2012). This body of work thus raises the possibility that a distinct frontal network is specifically recruited to integrate effort-related value.

On the other hand, these frontal regions (i.e. ACC, pre-SMA, AI, etc.) are also commonly implicated in cognitive control processes (Wu et al., 2020), which may overlap or obscure value signals. For example, valuebased decision-making may trigger cognitive control functions such as conflict detection and response inhibition (Botvinick and Braver, 2015; Botvinick et al., 2001), surprise and/or prediction error signaling (Vassena et al., 2020, 2017), and invigoration of goal-directed behavior (Kouneiher et al., 2009; Kurniawan et al., 2013; Mulert et al., 2005). Therefore, it is plausible that these regions are recruited to prepare and invigorate behaviors necessary for realizing a prospective reward instead of for computing prepotent net values per se. Cognitive control is also required for difficult decision-making, such as when two simultaneously presented options have similar net value (Chong et al., 2017; Hunt et al., 2012; Klein-Flügge et al., 2016; Massar et al., 2015), and in exploration/exploitation and foraging contexts, where individuals forego more immediate, secure rewards in order to search for alternative reward sources (Kolling et al., 2016; Shenhav et al., 2013). Indeed, studies that have independently manipulated net value and decision difficulty showed that these frontal regions, particularly the dorsal ACC, specifically tracked decision difficulty (Hogan et al., 2017; Westbrook et al., 2019) while, in contrast, the vmPFC uniquely tracked net value (Westbrook et al., 2019). Similarly, exploration of the reward environment - a behavior which is associated with increased cognitive control since it requires forgoing the "default" reward option in favor of uncertain rewards - also engages the dACC (Amiez et al., 2012; Cavanagh et al., 2012; although see Daw et al., 2006 for overlap with vmPFC). Taken together, these findings suggest that this distinct frontal network is recruited more specifically for cognitive control, such as response planning, option comparison, and foraging, whereas effort-related value integration is still processed in the core valuation network (e.g., vmPFC and VS) that have been identified in other cost domains.

The inconsistencies in previous studies may be related to several issues. For example, some may have been statistically underpowered due to small sample sizes, which may have reduced the probability of detecting significant effects, and/or reduce the reliability of their findings (Müller et al., 2018; Poldrack et al., 2017). Furthermore, the specific effort requirements of each task may have induced different patterns of brain activity, making it difficult to judge whether findings from individual studies can be generalized to the cognitive process of interest. A promising approach to address these issues is to quantitatively synthesize fMRI data across multiple studies using an image-based meta-analysis (Müller et al., 2018). Relative to traditional meta-analyses based only on peak coordinates of significant activity, an image-based meta-analytic approach uses the full information of the statistical maps from each study, and has greater power to detect small effect sizes (Luijten et al., 2017; Salimi-Khorshidi et al., 2009). A previous study showed that even the inclusion of $20 \%$ of statistical maps for included studies could significantly improve the precision of a meta-analysis (Radua et al., 2012).

Here, we conducted a hybrid coordinate- and image-based fMRI meta-analysis to identify the neural correlates of effort-related cost processing and value integration. Considering their critical roles in response planning, we hypothesized that frontal regions like the ACC, SMA, and AI would be consistently involved in representing prospective effort, independent of the reward offer. We also aimed to test whether effort-related net value integration (i.e., the integration of reward value with the effort required to obtain it) relied on the core valuation areas such as the vmPFC and VS or broader frontal regions.

\section{Materials and methods}

\subsection{Literature screen, data collection, and preparation}

\subsubsection{Exhaustive literature search}

We conducted a systematic literature search to identify neuroimaging studies on prospective effort and the integration of reward value and effort costs in healthy adults. Candidates for inclusion were initially identified by searching PubMed, ProQuest, and Web of Science on June 29, 2020 using the grouped terms ("fMRI" OR "functional magnetic resonance imaging") AND ("effort discounting" OR "effortbased decision-making" OR "effort valuation" OR "effort anticipation" OR "cost-benefit valuation" OR "cognitive effort" OR "physical effort" OR "effort expenditure" OR "effort allocation" OR "effortful goal directed action" OR "reward related motivation" OR "reward related effort"). Searches were limited to human studies where databases would allow. 121, 787, and 127 studies were identified on PubMed, ProQuest, and Web of Science, respectively. We also searched existing in-house reference libraries and names of prominent authors in the field, resulting in the addition of candidate studies. 934 candidate studies remained after search results were pooled and duplicates removed. Two researchers (PL-G, Y-WY) then independently reviewed the title and abstract of candidate papers to determine relevance, resulting in a pool of 72 studies that underwent a full-text review (Fig. 1).

\subsubsection{Inclusion/exclusion criteria}

Studies were included if they: 1) had a healthy adult human sample in the non-elderly age range (ages 18-65, with one exception detailed below); 2) used functional MRI; 3) either reported or referenced a whole-brain analysis; and 4) utilized a task with an effort component with clear effort (or combined effort and reward) cues during an 'anticipation' phase. Please note that 'anticipation' in this case refers to the evaluation of prospective effortful rewards before or during decision-making, and does not include anticipatory responses to reward post-effort exertion (e.g., the 'evaluation' phase described in Assadi et al. (2009)).

To ensure that the selected studies could be meaningfully compared, 


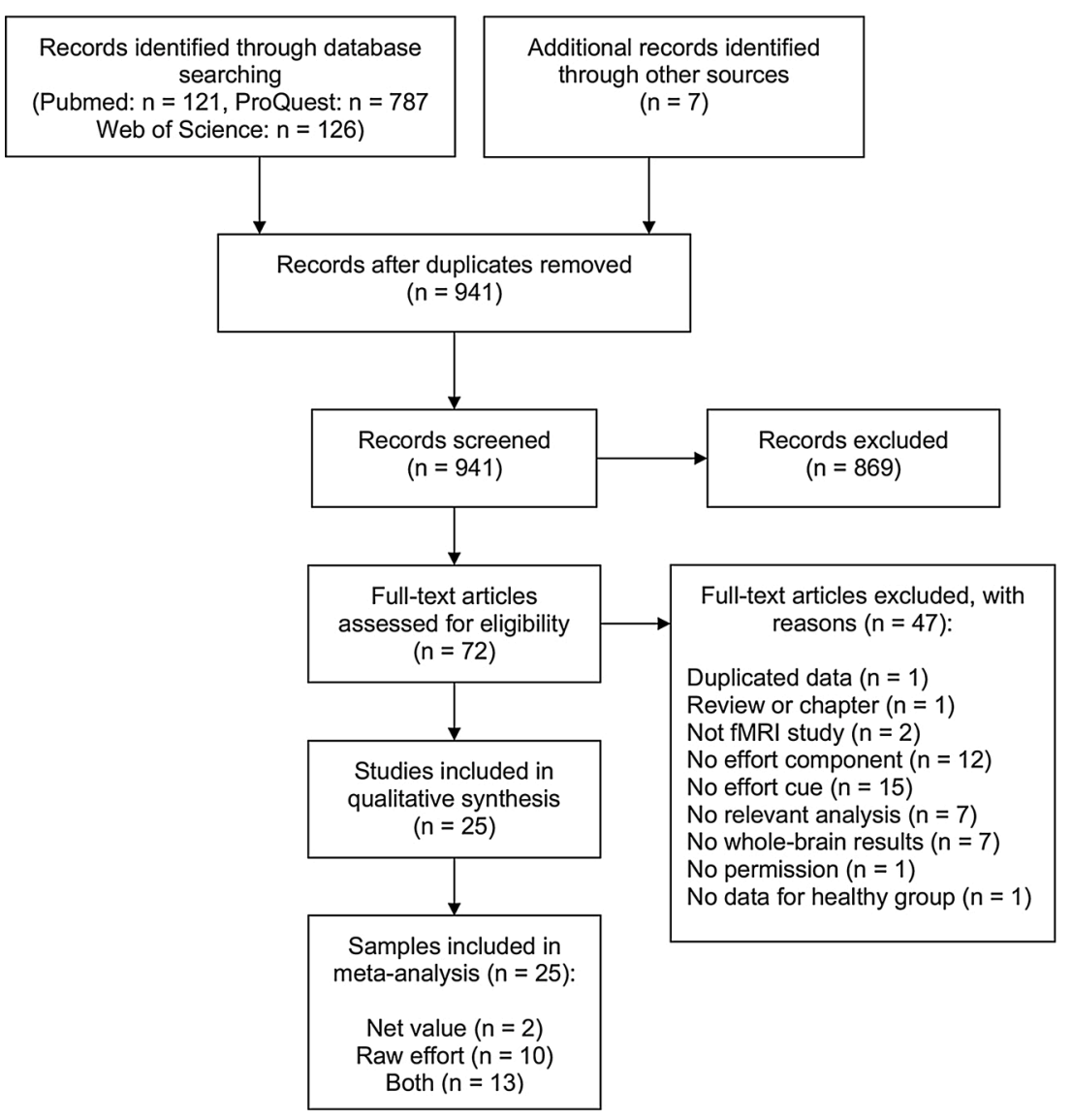

Fig. 1. Preferred Reporting Items for Systematic Reviews and Meta-Analyses (PRISMA) flow diagram.

we limited the final corpus to those that used experimental paradigms with certain characteristics. First, because studies have found that loss and gain are asymmetric and partially dissociable (Chen et al., 2020; Porat et al., 2014; Tanaka et al., 2014), we excluded studies that used paradigms with only loss conditions, or that only conducted gain vs loss comparisons. Second, we excluded studies that only used a single speeded response as its effort component (e.g. classical Monetary Incentive Delay task (Knutson et al., 2000)), as this was not deemed as a significant effort demand, and other reviews and meta-analyses focusing on reward anticipation with these paradigms can be found elsewhere (Diekhof et al., 2012; Knutson and Greer, 2008; Wilson et al., 2018). Finally, we only included those studies which measured activity during the prospective valuation of an action and its rewards, rather than only at the time of reward outcome, as estimates of previously expended effort can be biased by reward receipt (Pooresmaeili et al., 2015).

We contacted the corresponding authors of 28 candidate studies to request whole-brain statistical maps for the analyses of interest, and received whole-brain statistical maps or peak coordinates from 25 studies. In cases where only between-group (e.g. clinical studies) and/or ROI results were reported, we contacted corresponding authors to inquire about the availability of whole-brain results for relevant contrasts in healthy adult subjects. If images were not available, we requested they provide us with peak foci in stereotactic spatial coordinates (i.e., Talairach or MNI space), together with the direction of the effect (positive or negative).

\subsubsection{Data collection and preparation}

We performed two analyses of interest. The first examined activity related to the raw effort involved in the option itself. We included analyses that examined high vs. low effort demands (i.e., categorical contrasts) and those that examined continuous changes in effort (i.e., parametric modulation). The second analysis examined activity related to the prospective net value of an effortful reward. Whenever possible, we used the contrast related to the net value of a single option (i.e., the subjective value of the chosen option discounted by the effort required to obtain it). When this contrast was unavailable, we used the contrast related to the differences between options instead. Studies that only investigated BOLD activity associated with interactions between reward and effort were excluded, as they did not rely on the same discounting assumptions as other measures of net value. It should be noted that one study (Nagase et al., 2018) included two experiments with six common participants, so we selected the experiment with a larger sample size for the meta-analysis. In another study (Chong et al., 2017), all participants took part in both cognitive and physical effort-based decision-making tasks. Thus, we combined the statistical maps from both tasks to avoid selection bias. Finally, one study (Seaman et al., 2018) had a sample that included participants ranging from 22 to 83 years old. However, the authors of this study provided whole-brain maps that controlled for the effect of age, and we chose to include this data in the net value meta-analysis.

\subsubsection{Final corpus}

As shown in Fig. 1, 25 studies were ultimately included in the final corpus of studies, which were considered in one or both meta-analyses on raw effort evaluation and effort-reward integration. The raw effort valuation analysis included 15 maps (65\%) and 8 coordinates for raw effort processing, resulting in 23 studies, with a total sample of $\mathrm{N}=549$ (mean age $=24.95$; median $=22.5$, range $=[16-50]$ ). A description of the final corpus of studies can be found in Table 1 . The net value analysis included 11 maps (73\%) and 4 coordinates, resulting in 15 studies, with a total sample of $\mathrm{N}=428$ participants (mean age $=28.5$; median $=23$, range $=[16-75])$. 
Table 1

Summary of Included Studies.

\begin{tabular}{|c|c|c|c|c|c|c|c|c|}
\hline Study & $\mathrm{N}$ & Task Type & $\begin{array}{l}\text { Effort Type } \\
\text { (Description) }\end{array}$ & $\begin{array}{l}\text { Effort } \\
\text { exertion }\end{array}$ & Analysis & Data Type & Parameter & Net value calculation \\
\hline \multirow[t]{2}{*}{$\begin{array}{l}\text { Aridan et al., } \\
2019\end{array}$} & 40 & Choice & $\begin{array}{l}\text { Physical } \\
\text { (Handgrip) }\end{array}$ & $\begin{array}{l}\text { Offline (1 } \\
\text { trial) }\end{array}$ & $\begin{array}{l}\text { Net } \\
\text { value }\end{array}$ & Map & Prob(yes) & $\beta_{1} \cdot R+\beta_{2} \cdot L+\beta_{3} \cdot E$ \\
\hline & & & & Effort & Map & $\begin{array}{l}\text { Parametric } \\
\text { effort demand }\end{array}$ & & \\
\hline \multirow[t]{2}{*}{$\begin{array}{l}\text { Arulpragasam } \\
\text { et al., } 2018\end{array}$} & 28 & Choice & $\begin{array}{l}\text { Physical (Key } \\
\text { press) }\end{array}$ & $\begin{array}{l}\text { Offline } \\
\text { (all) }\end{array}$ & $\begin{array}{l}\text { Net } \\
\text { value }\end{array}$ & Map & SV of Chosen Option & $R-k \cdot E^{\rho}$ \\
\hline & & & & & Effort & Map & $\begin{array}{l}\text { Effort demand of } \\
\text { the variable option } \\
\text { (at Cue 1) }\end{array}$ & \\
\hline \multirow[t]{2}{*}{$\begin{array}{l}\text { Bernacer et al., } \\
2019\end{array}$} & 24 & Choice & $\begin{array}{l}\text { Physical } \\
\text { (Running) }\end{array}$ & $\begin{array}{l}\text { Offline (1 } \\
\text { trial) }\end{array}$ & $\begin{array}{l}\text { Net } \\
\text { value }\end{array}$ & Map & SV Difference & $\begin{array}{l}\text { Hyperbolic, exponential, or double exponential } \\
\text { discounting model based on individual model } \\
\text { fit }\end{array}$ \\
\hline & & & & & Effort & Map & Max $>$ no effort & \\
\hline \multirow[t]{3}{*}{$\begin{array}{l}\text { Bonnelle et al., } \\
2016\end{array}$} & 37 & Choice & $\begin{array}{l}\text { Physical } \\
\text { (Handgrip) }\end{array}$ & $\begin{array}{l}\text { Online } \\
\text { (all) }\end{array}$ & $\begin{array}{l}\text { Net } \\
\text { value }\end{array}$ & Coordinates & Expected Reward & $R\left(\frac{\text { force }}{M V C}-(E-0.3)\right)$ \\
\hline & & & & & Effort & Coordinates & $\begin{array}{l}\text { Parametric effort } \\
\text { demand }\end{array}$ & \\
\hline & & & Physical & & & & & Physical: $R-k \cdot E^{2}$ \\
\hline \multirow[t]{2}{*}{$\begin{array}{l}\text { Chong et al., } \\
2017^{\mathrm{a}}\end{array}$} & 34 & Choice & $\begin{array}{l}\text { (Handgrip) } \\
\text { +Cognitive } \\
\text { (RSVP) }\end{array}$ & $\begin{array}{l}\text { Offline } \\
\text { (10 trials) }\end{array}$ & $\begin{array}{l}\text { Net } \\
\text { value }\end{array}$ & Map & SV Difference & $\begin{array}{l}\text { Cognitive: } \frac{R}{1+k \cdot E} \text { (based on model } \\
\text { comparisons) }\end{array}$ \\
\hline & & & & & Effort & Map & $\begin{array}{l}\text { Parametric effort } \\
\text { demand }\end{array}$ & \\
\hline \multirow[t]{2}{*}{$\begin{array}{l}\text { Croxson et al., } \\
2009\end{array}$} & 16 & No choice & $\begin{array}{l}\text { Physical } \\
\text { (Trackball) }\end{array}$ & $\begin{array}{l}\text { Online } \\
\text { (all) }\end{array}$ & $\begin{array}{l}\text { Net } \\
\text { value }\end{array}$ & Coordinates & Log net value & $\log \left[f_{0}\right]\left(\frac{R}{E}\right)$ \\
\hline & & & & & Effort & Coordinates & $\begin{array}{l}\text { Increasing effort } \\
\text { level }\end{array}$ & \\
\hline \multirow{2}{*}{$\begin{array}{l}\text { Gaillard et al., } \\
2019 \\
\text { Grodin et al., } \\
2016\end{array}$} & 23 & No Choice & $\begin{array}{l}\text { Cognitive } \\
\text { (Spatial WM) }\end{array}$ & $\begin{array}{l}\text { Online } \\
\text { (all) }\end{array}$ & Effort & Map & $\begin{array}{l}\text { Categorial High vs } \\
\text { Low WM Load }\end{array}$ & \\
\hline & 17 & No Choice & $\begin{array}{l}\text { Physical (Key } \\
\text { press) }\end{array}$ & $\begin{array}{l}\text { Online } \\
\text { (all) }\end{array}$ & Effort & Map & $\begin{array}{l}\text { Categorical High vs } \\
\text { Low effort }\end{array}$ & \\
\hline $\begin{array}{l}\text { Hauser et al., } \\
2017\end{array}$ & 28 & $\begin{array}{l}\text { Reward/ } \\
\text { effort } \\
\text { learning }\end{array}$ & $\begin{array}{l}\text { Physical } \\
\text { (Handgrip) }\end{array}$ & $\begin{array}{l}\text { Online } \\
\text { (all) }\end{array}$ & Effort & Map & $\begin{array}{l}\text { Parametric } \\
\text { expected effort } \\
\text { demand }\end{array}$ & \\
\hline $\begin{array}{l}\text { Hogan et al., } \\
2019\end{array}$ & 34 & Choice & $\begin{array}{l}\text { Physical } \\
\text { (Handgrip) }\end{array}$ & $\begin{array}{l}\text { Offline } \\
\text { (10 trials) }\end{array}$ & $\begin{array}{l}\text { Net } \\
\text { value }\end{array}$ & Map & SV of chosen option & $-(-E)^{\rho}$ \\
\hline \multirow[t]{2}{*}{$\begin{array}{l}\text { Klein-Flügge } \\
\text { et al., } 2016\end{array}$} & 21 & Choice & $\begin{array}{l}\text { Physical } \\
\text { (Handgrip) }\end{array}$ & $\begin{array}{l}\text { Online } \\
(30 \% \\
\text { trials })\end{array}$ & $\begin{array}{l}\text { Net } \\
\text { value }\end{array}$ & Map & SV difference & $R\left(1-\left(\frac{1}{1+e^{-k(E-p)}}-\frac{1}{1+e^{k p}}\right)\left(1+\frac{1}{e^{k p}}\right)\right)$ \\
\hline & & & & & Effort & Map & $\begin{array}{l}\text { Parametric Effort } \\
\text { Difference }\end{array}$ & \\
\hline \multirow[t]{2}{*}{$\begin{array}{l}\text { Kurniawan } \\
\text { et al., } 2010\end{array}$} & 17 & Choice & $\begin{array}{l}\text { Physical } \\
\text { (Handgrip) }\end{array}$ & $\begin{array}{l}\text { Offline } \\
\text { (75\% } \\
\text { trials) }\end{array}$ & $\begin{array}{l}\text { Net } \\
\text { value }^{\mathrm{b}}\end{array}$ & Coordinates & $\begin{array}{l}\text { Choice } \times \text { effort } \\
\text { interaction (choice } \\
\text { to grip }>\text { choice to } \\
\text { hold) }\end{array}$ & \\
\hline & & & & & Effort & Coordinates & $\begin{array}{l}\text { High }>\text { low effort of } \\
\text { chosen option }\end{array}$ & \\
\hline $\begin{array}{l}\text { Kurniawan } \\
\text { et al., } 2013\end{array}$ & 19 & No Choice & $\begin{array}{l}\text { Physical } \\
\text { (Handgrip) }\end{array}$ & $\begin{array}{l}\text { Online } \\
(50 \% \\
\text { trials })\end{array}$ & Effort & Map & $\begin{array}{l}\text { High }>\text { low effort } \\
\text { demand }\end{array}$ & \\
\hline \multirow[t]{2}{*}{$\begin{array}{l}\text { Massar et al., } \\
2015\end{array}$} & 23 & Choice & $\begin{array}{l}\text { Cognitive } \\
\text { (Backwards } \\
\text { typing) }\end{array}$ & $\begin{array}{l}\text { Offline (1 } \\
\text { trial) }\end{array}$ & $\begin{array}{l}\text { Net } \\
\text { value }\end{array}$ & Map & SV of chosen option & $\begin{array}{l}\text { Indifference points from the experimental } \\
\text { calibration }\end{array}$ \\
\hline & & & & & Effort & Map & $\begin{array}{l}\text { Parametric effort } \\
\text { level }\end{array}$ & \\
\hline $\begin{array}{l}\text { Nagase et al., } \\
2018\end{array}$ & 33 & $\begin{array}{l}\text { Reward/ } \\
\text { effort } \\
\text { learning }\end{array}$ & $\begin{array}{l}\text { Cognitive } \\
\text { (Arithmetic) }\end{array}$ & $\begin{array}{l}\text { Online } \\
\text { (all) }\end{array}$ & Effort & Map & $\begin{array}{l}\text { Expected effort } \\
\text { demand of chosen } \\
\text { option }\end{array}$ & \\
\hline Park et al., 2017 & 30 & No Choice & $\begin{array}{l}\text { Physical (Mouse } \\
\text { click) }\end{array}$ & $\begin{array}{l}\text { Online } \\
\text { (all) }\end{array}$ & Effort & Coordinates & $\begin{array}{l}\text { High vs low effort } \\
\text { demand }\end{array}$ & \\
\hline \multirow[t]{2}{*}{$\begin{array}{l}\text { Prévost et al., } \\
2010\end{array}$} & 16 & Choice & $\begin{array}{l}\text { Physical } \\
\text { (Handgrip) }\end{array}$ & $\begin{array}{l}\text { Online } \\
\text { (all) }\end{array}$ & $\begin{array}{l}\text { Net } \\
\text { value }\end{array}$ & Coordinates & $\begin{array}{l}\text { SV of variable } \\
\text { option }\end{array}$ & $\frac{R}{1+k \cdot E}$ \\
\hline & & & & & Effort & Coordinates & $\begin{array}{l}\text { Parametric Effort } \\
\text { Demand }\end{array}$ & \\
\hline $\begin{array}{l}\text { Sayalı and } \\
\text { Badre, } 2019\end{array}$ & 50 & Choice & $\begin{array}{l}\text { Cognitive (Cued } \\
\text { task switching) }\end{array}$ & $\begin{array}{l}\text { Online } \\
\text { (all) }\end{array}$ & Effort & Map & $\begin{array}{l}\text { Expected effort } \\
\text { demand of chosen } \\
\text { option }\end{array}$ & \\
\hline \multirow[t]{3}{*}{$\begin{array}{l}\text { Scholl et al., } \\
2015\end{array}$} & 20 & $\begin{array}{l}\text { Reward/ } \\
\text { effort } \\
\text { learning }\end{array}$ & $\begin{array}{l}\text { Physical } \\
\text { (Trackball) }\end{array}$ & $\begin{array}{l}\text { Online } \\
\text { (all) }\end{array}$ & $\begin{array}{l}\text { Net } \\
\text { value }\end{array}$ & Map & $\begin{array}{l}\text { Decision value } \\
\text { difference }\end{array}$ & $\frac{R+\delta \cdot \operatorname{Prob}+\gamma \cdot E}{1+\delta+\gamma}$ \\
\hline & & & & & Effort & Map & $\begin{array}{l}\text { Effort demand } \\
\text { difference }\end{array}$ & \\
\hline & 75 & Choice & & & & Map & SV of chosen option & \\
\hline
\end{tabular}


Table 1 (continued)

\begin{tabular}{|c|c|c|c|c|c|c|c|c|}
\hline Study & $\mathrm{N}$ & Task Type & $\begin{array}{l}\text { Effort Type } \\
\text { (Description) }\end{array}$ & $\begin{array}{l}\text { Effort } \\
\text { exertion }\end{array}$ & Analysis & Data Type & Parameter & Net value calculation \\
\hline $\begin{array}{l}\text { Seaman et al., } \\
2018\end{array}$ & & & $\begin{array}{l}\text { Physical } \\
\text { (Keyboard) }\end{array}$ & $\begin{array}{l}\text { Online } \\
(50 \% \\
\text { trials) }\end{array}$ & $\begin{array}{l}\text { Net } \\
\text { value }\end{array}$ & & & $\frac{R}{1+k \cdot E}$ \\
\hline \multirow[t]{2}{*}{$\begin{array}{l}\text { Skvortsova } \\
\text { et al., } 2014\end{array}$} & 20 & $\begin{array}{l}\text { Reward/ } \\
\text { effort } \\
\text { learning }\end{array}$ & $\begin{array}{l}\text { Physical } \\
\text { (Handgrip) }\end{array}$ & $\begin{array}{l}\text { Online } \\
\text { (all) }\end{array}$ & $\begin{array}{l}\text { Net } \\
\text { value }\end{array}$ & Map & $\begin{array}{l}\text { Expected value } \\
\text { demand of chosen } \\
\text { option }\end{array}$ & $R-k \cdot E$ (based on model comparisons) \\
\hline & & & & & Effort & Map & Effort Q & \\
\hline \multirow[t]{2}{*}{$\begin{array}{l}\text { Stoppel et al., } \\
2011\end{array}$} & 18 & No Choice & $\begin{array}{l}\text { Cognitive (Line } \\
\text { tracing) }\end{array}$ & $\begin{array}{l}\text { Online } \\
\text { (all) }\end{array}$ & $\begin{array}{l}\text { Net } \\
\text { value }^{b}\end{array}$ & Coordinates & Reward $\times$ difficulty & \\
\hline & & & & & Effort & Coordinates & Hard > easy effort & \\
\hline \multirow[t]{2}{*}{$\begin{array}{l}\text { Suzuki et al., } \\
2020\end{array}$} & 19 & Choice & $\begin{array}{l}\text { Physical } \\
\text { (Keypress) }\end{array}$ & $\begin{array}{l}\text { Offline } \\
\text { (all) }\end{array}$ & $\begin{array}{l}\text { Net } \\
\text { value }\end{array}$ & Coordinates & SV of chosen option & $R-k \cdot E^{p}$ \\
\hline & 29 & No Choice & $\begin{array}{l}\text { Physical (Maze } \\
\text { Navigation) }\end{array}$ & $\begin{array}{l}\text { Online } \\
\text { (all) }\end{array}$ & Effort & Coordinates & High $>$ low effort & \\
\hline $\begin{array}{l}\text { Vassena et al., } \\
2014\end{array}$ & 22 & No Choice & $\begin{array}{l}\text { Cognitive } \\
\text { (Arithmetic) }\end{array}$ & $\begin{array}{l}\text { Online } \\
\text { (all) }\end{array}$ & Effort & Coordinates & High $>$ low effort & \\
\hline \multirow[t]{2}{*}{$\begin{array}{l}\text { Westbrook et al., } \\
2019\end{array}$} & 21 & Choice & $\begin{array}{l}\text { Cognitive (N- } \\
\text { back) }\end{array}$ & $\begin{array}{l}\text { Offline }(1 \\
\text { trial) }\end{array}$ & $\begin{array}{l}\text { Net } \\
\text { value }\end{array}$ & Map & $\begin{array}{l}\text { SV of the more } \\
\text { effortful option }\end{array}$ & $\begin{array}{l}\text { Indifference points from the experimental } \\
\text { calibration }\end{array}$ \\
\hline & & & & & Effort & Map & Effort demand & \\
\hline
\end{tabular}

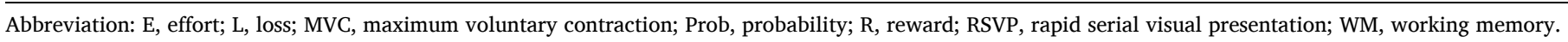

a Maps from separate tasks were combined for all analyses.

b Only included in supplementary Net Value analysis.

\subsection{Meta-analytic procedures}

\subsubsection{Seed-based d Mapping}

Because the inclusion of statistical maps can substantially increase the sensitivity of meta-analyses (Radua et al., 2012), we chose to perform combined image- and coordinate-based meta-analyses using the software Seed-based $d$ Mapping with Permutation of Subject Images (SDM-PSI, version 6.21; https://www.sdmproject.com). SDM-PSI preserves the information about the sign of the effect and the methods have been validated in previous studies (Albajes-Eizagirre et al., 2019; Radua et al., 2012). During preprocessing, SDM-PSI recreated voxel-level maps of standardized effect sizes (i.e., Hedge's g) and their variances and allowed the incorporation of both whole-brain t-maps and peak information (i.e., coordinates and t-values). Specifically, in the case where raw study images were available, effect sizes were estimated from the $t$, $\mathrm{z}$, or $\mathrm{p}$ values of the map. However, when $t$-maps were unavailable, SDM-PSI used anisotropic kernels estimate lower and upper effect-size bounds for each study from reported coordinates and their respective t-values (Radua et al., 2014).

\subsubsection{Meta-analysis}

Two separate whole-brain meta-analyses were conducted to examine consistent neural correlates of prospective effort and net value processing, respectively. SDM-PSI meta-analysis has been described in more detail elsewhere (Albajes-Eizagirre et al., 2019). Briefly, after pre-processing, maximum likelihood estimation (MLE) is used to initially estimate the voxel-wise mean effect sizes and variances. Next, study and subject images were imputed 50 times (Albajes-Eizagirre et al., 2019; Luijten et al., 2017). Using Rubin's rules, SDM-PSI then combines subject images from the different imputations into single combined meta-analysis image. Random-effect models were then used to assess the mean effect size of each study, where the weight of a study is the inverse of the sum of its variance and the between-study variance. SDM z-maps were generated by dividing the voxel-wise effect sizes by their standard errors. As these z-values may deviate from a normal distribution, a null-distribution was estimated for each meta-analysis from 50 whole-brain permutations, as is standard in SDM-PSI.

2.2.2.1. Region-of-interest (ROI) analysis. To directly investigate the involvement of key brain regions in effort-related cost processing and value integration, we focused on seven a priori regions of interest (ROIs) derived from an independent meta-analysis (Bartra et al., 2013) that examined valuation network in general. Those ROIs included: the vmPFC, right and left VS, ACC, pre-SMA, and right and left AI, which generally covered the core valuation network and additional frontal regions of interest. A spherical mask of radius $6 \mathrm{~mm}$ was created for each ROI centered on the respective peak coordinates. Effect sizes and variances of those ROIs were extracted from each study and plotted as forest plots. We used the metafor package (Viechtbauer, 2010) in $\mathrm{R}$ version 4.0.3 (https://www.r-project.org) to calculate mean effect sizes and 95 $\%$ confidence intervals for each ROI, as this package allows for specification of variance estimates from each study.

2.2.2.2. Whole-brain analysis. We also examined the whole-brain results beyond these a priori ROIs. To reduce the false-positive results due to multiple comparisons, we applied a familywise error (FWE) correction with 1000 subject-based permutations (Albajes-Eizagirre et al., 2019). In accordance with SDM-PSI's recommendations, a threshold-free cluster enhancement (TFCE) corrected $p<0.025$ was used (Albajes-Eizagirre et al., 2019).

In addition, we performed a conjunction analysis to identify regions that were associated with both raw effort demand and net value. For exploratory purposes, we created maps using a voxel-level uncorrected threshold of $p<0.001$ and a cluster size $>20$ voxels for both metaanalyses. Masks were generated from significant clusters scaled positively or negatively with either raw effort demand or net value (i.e., based on absolute values). We then used SPM12 (http:/ /www.fil.ion.ucl. ac.uk/spm) to perform a conjunction analysis to extract overlapping areas for both processes, regardless of the direction (Cutler and Campbell-Meiklejohn, 2019).

Because of the high level of heterogeneity of task features and parameters between studies, we were interested in assessing if our findings were driven by a specific design. Specifically, tasks varied in effort type (i.e. cognitive effort vs. physical effort), probability of effort execution (online vs offline effort), and net value parameter (single net value vs. value difference between two options). However, direct comparisons would be underpowered, as too few studies contained specific task features. Thus, in order to explore if studies with certain task features showed patterns of activity that were unique and/or overlapping to activations patterns identified in the main analyses, we conducted 6 supplementary meta-analyses using subgroups of studies $(\mathrm{N} \geq 10$ studies in a subgroup) from the main raw effort and net value analyses.

First, in order to identify regions involved in signaling prospective physical effort demands and integration of physical effort costs with 
reward, we repeated both raw effort and net value analyses with a subgroup of studies using physical effort tasks $(\mathrm{N}=16$ and $\mathrm{N}=13$, respectively). Note in the case of studies that had both physical and cognitive effort tasks (i.e. Chong et al. (2017)), only maps from the physical effort task were used.

Second, in many effort-based decision-making studies, subjects were required to either execute the effort immediately after a choice (i.e., online execution) or execute the effort (or a random sample) at the end of the task (i.e., offline execution). Thus, to examine if regions consistently engaged in raw effort valuation overlapped with regions involved in signaling purely immediate effort requirements, we conducted a subgroup analysis that investigated prospective effort signaling in tasks using real online effort $(\mathrm{N}=16)$.

Third, because of the possible role of the dorsal ACC and other frontal regions in signaling choice difficulty, we were interested in assessing if our findings were influenced by studies that used net value differences as the parameter, rather than the net value of the chosen option. Thus, we repeated the meta-analysis with a subgroup of studies that used parameters only representing the net value of a single option $(\mathrm{N}=11)$.

Fourth, because net value can also be more broadly defined as an interaction between reward and effort, we repeated the net value metaanalysis by including the coordinates of two additional studies (Kurniawan et al., 2010; Stoppel et al., 2011) that used interaction parameters (e.g. Reward $\times$ Effort) as opposed to traditional discounting parameters of net value (e.g. SV).

Finally, although the neural correlates of raw reward have been widely examined in previous studies (e.g., Bartra et al., 2013; Sescousse et al., 2013), for the confirmatory purpose, we conducted a raw reward analysis based on studies that examined reward processing $(\mathrm{N}=13)$. These analyses were conducted using the same procedures described above.

\subsubsection{Heterogeneity and publication bias}

Significant clusters were assessed for heterogeneity, or the degree of between-study variance due to other factors (e.g. differences in analytical approaches, subject populations, etc.) aside from random error. For each meta-analysis, peaks with heterogeneity $l^{2}$ values $>20 \%$ were flagged and inspected. Although it has been suggested that $l^{2}$ statistics are inflated in small sample meta-analyses (Von Hippel, 2015), we note any clusters with high $l^{2}$ values $>20 \%$, values, as results from these clusters may be driven by other factors rather than chance.

Publication bias, or the favoring of publishing significant, as opposed to null, findings, can inflate meta-analysis effect sizes. In order to assess publication bias, we created funnel plots for peak voxels of significant clusters in which Hedge's $g$ effect size estimates were plotted against a measure of precision (i.e. variance of Hedge's $g$ estimate). Funnel plots for each cluster were visually inspected for asymmetry, which would suggest that reported effect sizes are related to their statistical significance. For each significant cluster, Egger regression tests (Egger et al., 1997) were also conducted to quantitatively test if the number of studies with statistically significant results is larger than expected. Significant results in an Egger regression would indicate the possible existence of unpublished studies with non-significant effects. These statistics are reported alongside the effect sizes for each significant cluster.

\subsection{Data availability}

The protocol for this study was not pre-registered. However, unthresholded z-maps of our results are available at NeuroVault: https://neurovault.org/collections/9286/. The TFCE-corrected maps as well as publication bias and heterogeneity data are available from the corresponding authors upon request.

\section{Results}

\subsection{ROI analysis}

To directly examine the roles of key regions in raw effort prospect and effort-reward integration, we focused on seven a priori ROIs. Results are summarized in Table 2 . The vmPFC consistently showed positive associations with net value and negative associations with raw effort. The bilateral VS showed a similar response pattern, but smaller effect sizes for both analyses. In contrast, the pre-SMA scaled positively with raw effort and, albeit more variably, negatively with net value. The ACC and bilateral AI showed a similar response pattern, but smaller effect sizes for both analyses. Figs. 2 and 3 show the Hedge's $g$ effect sizes for raw effort and net value analyses in the vmPFC and pre-SMA ROIs. The forest plots for other regions were shown in Figs. S1-S10.

To statistically test the opposite response patterns of the vmPFC and pre-SMA, we focused on studies with both raw effort and net value data $(\mathrm{N}=13)$ and conducted a linear mixed-effects model with Measure (Effort and Net Value), Region (vmPFC and pre-SMA), and their interaction as fixed effects, study as a random effect, and Hedge's $g$ effect sizes as the dependent variable. As expected, the analysis identified a significant interaction between Measure and Region $(\beta=-0.83, Z=$ $-7.16, p<0.001$ ), such that, for vmPFC, effect sizes were more positive for net value than effort. Conversely, for pre-SMA, effect sizes more positive for effort than net value (see Table S1 and Fig. S11).

Finally, to explore the hierarchical structure of the seven ROIs during raw effort and net value processing, we examined the correlations between effect sizes of these regions across studies. As shown in Fig. S12, the correlation map for the raw effort analysis revealed two distinct networks, with one including the vmPFC and bilateral VS, and the other including the pre-SMA, ACC, and bilateral AI. The pattern is less clear for the net value analysis (Fig. S13), where the vmPFC activity did not show strong correlations with other regions, possibly due to its low variance (i.e., high consistency) across studies. Other regions showed high correlations across studies. These findings further suggest that the vmPFC and pre-SMA may play opposite roles in effort-related cost encoding and net value computation, although the correlation maps identified here are complex and more evidence is still needed to elucidate how these regions interact with each other during effort-based valuation.

\subsection{Whole-brain analysis}

\subsubsection{Raw effort}

We first examined brain regions that were consistently associated with raw effort processing. As illustrated in Fig. 4a, the analysis yielded positive effects clustered in the right pre-SMA and adjacent caudal ACC (see Table 3). At a more lenient, uncorrected $p<0.001$ threshold, other positive foci were detected in the left SMA, right precuneus, and left middle frontal gyrus, and negative foci were detected in the bilateral vmPFC/OFC and left middle temporal gyrus. Heterogeneity $I^{2}$ statistics, funnel plots and Egger regressions did not detect excess heterogeneity or publication bias in any significant clusters in the TFCE-corrected findings. However, in the uncorrected analysis, a cluster in the right precuneus was found to be associated with extreme heterogeneity $\left(I^{2}=\right.$ $59.50 \%)$.

\subsubsection{Net value}

Next, we examined brain regions that were consistently associated with net value encoding. As illustrated in Fig. 4b, the analysis yielded a large cluster connecting cortical and subcortical regions of the medial PFC, VS, dorsal striatum (bilateral putamen and left caudate), and temporal gyrus (see Table 3). Moreover, a cluster consisting of the bilateral medial and posterior cingulate cortex and precuneus and a separate cluster in the left middle frontal gyrus also showed significantly positive associations. Some small clusters, including the left SMA, right dorsolateral PFC (dlPFC), and right superior frontal gyrus, scaled 
Table 2

Results of ROI analyses.

\begin{tabular}{|c|c|c|c|c|c|c|c|}
\hline ROI & MNI coordinate & Analysis & Hedge's $g$ & $Z$ & $p$ & $I^{2}$ (in \%) & Egger's $p$ \\
\hline \multirow[t]{2}{*}{ vmPFC } & $(2,46,-8)$ & Net value & 0.31 & 6.19 & $<0.01$ & $<0.01$ & 0.61 \\
\hline & & Raw effort & -0.14 & -3.18 & $<0.01$ & 1.51 & 0.83 \\
\hline \multirow[t]{2}{*}{ rVS } & $(12,10,-6)$ & Net value & 0.18 & 3.13 & $<0.01$ & 22.48 & 0.92 \\
\hline & & Raw effort & -0.002 & -0.05 & 0.95 & 8.06 & 0.45 \\
\hline \multirow[t]{2}{*}{ IVS } & $(-12,12,-6)$ & Net value & 0.14 & 2.44 & 0.02 & 25.16 & 0.74 \\
\hline & & Raw effort & -0.05 & -1.10 & 0.27 & $<0.01$ & 0.93 \\
\hline \multirow[t]{2}{*}{ Pre-SMA } & $(-2,16,46)$ & Net value & -0.27 & -2.62 & $<0.01$ & 73.04 & 0.12 \\
\hline & & Raw effort & 0.17 & 3.02 & $<0.01$ & 39.67 & 0.92 \\
\hline \multirow[t]{2}{*}{ ACC } & $(-2,28,28)$ & Net value & -0.11 & -1.19 & 0.23 & 69.07 & 0.22 \\
\hline & & Raw effort & 0.08 & 1.75 & 0.08 & 12.59 & 0.82 \\
\hline \multirow[t]{2}{*}{ rAI } & $(32,20,-6)$ & Net value & -0.12 & -1.50 & 0.14 & 55.31 & 0.21 \\
\hline & & Raw effort & 0.08 & 1.86 & 0.06 & $<0.01$ & 0.34 \\
\hline \multirow[t]{2}{*}{ IAI } & $(-30,22,-6)$ & Net value & -0.06 & -0.73 & 0.46 & 63.17 & 0.16 \\
\hline & & Raw effort & 0.03 & 0.83 & 0.41 & 0.69 & 0.51 \\
\hline
\end{tabular}

Abbreviations: ACC, anterior cingulate cortex; AI, anterior insula; 1, left; $r$, right, vmPFC, ventromedial prefrontal cortex; VS, ventral striatum. The significant results are indicated in bold font.

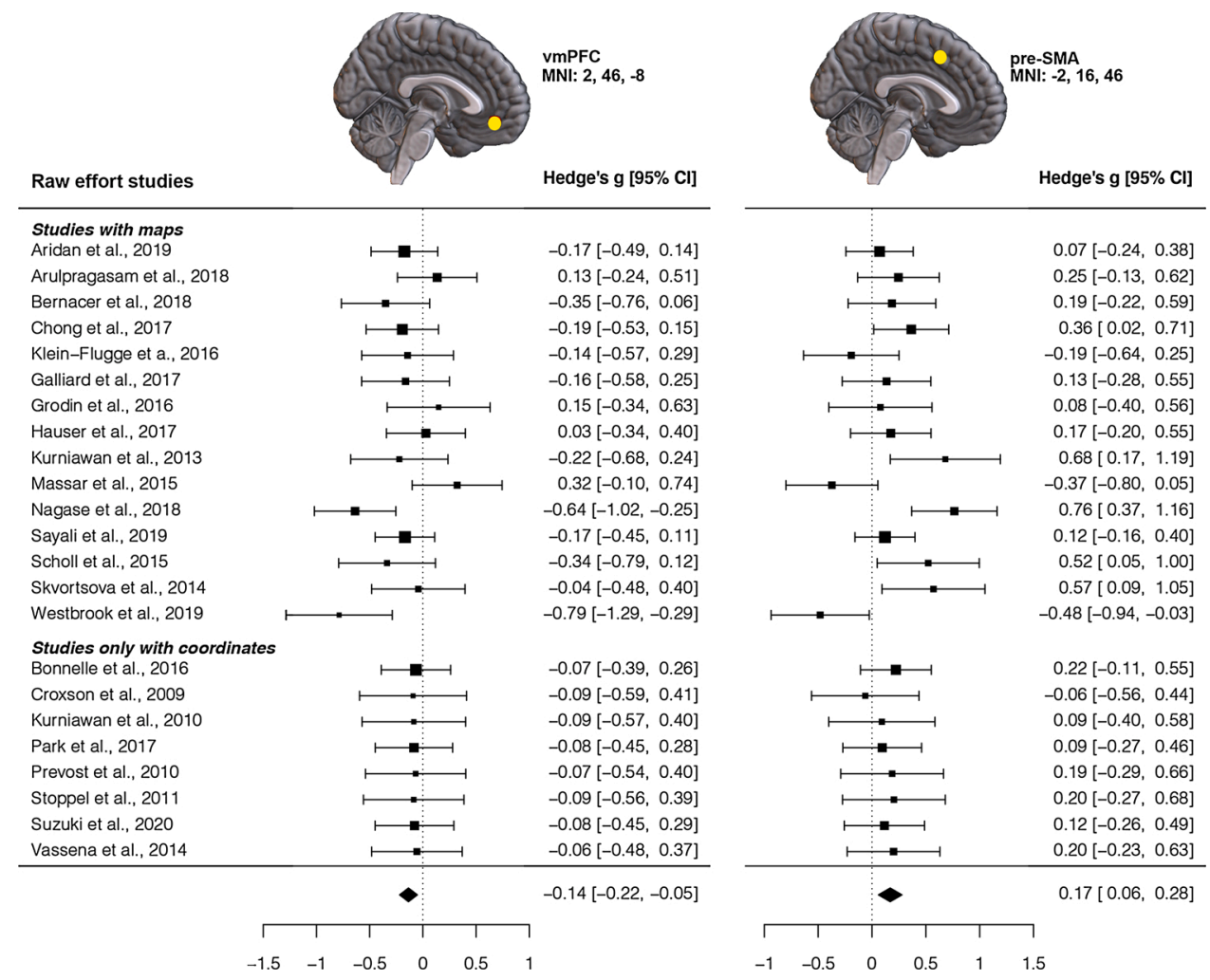

Fig. 2. Forest plot illustrating neural correlates of effort demand in the vmPFC and pre-SMA ROIs. The pre-SMA is positively associated with raw effort (Hedge's $g=$ $0.20,95 \% \mathrm{CI}[0.02,0.37]$ ), whereas the vmPFC showed a negative association (Hedge's $\mathrm{g}=-0.17,95 \% \mathrm{CI}[-0.30,-0.03]$ ).

negatively with net value, although these results were only detectable at a lenient uncorrected $p<0.001$ threshold.

In addition, heterogeneity $I^{2}$ statistics, funnel plots and Egger regressions showed no evidence of excess heterogeneity or publication bias in any of the significant clusters for the main net value or single SV subgroup TFCE-corrected results. No evidence of publication bias was detected in the uncorrected net value analysis, however negative clusters the left SMA and right dIPFC had $I^{2}$ statistics of $64.09 \%$ and $50.05 \%$ respectively, suggesting that findings in these two regions were highly heterogenous.

\subsubsection{Conjunction analysis}

Finally, we performed a conjunction analysis to identify areas that are sensitive to both net value and effort requirements. Due to the exploratory nature of this analysis, we used a lenient threshold of uncorrected $\mathrm{p}<0.001$ at voxel level and $\mathrm{k}>20$ at cluster level. Note that we used absolute values in the conjunction analysis because of the opposite response pattern found in the main prospective effort and net value meta-analyses. We found that the vmPFC and left lateral orbitofrontal cortex scaled positively with net value and negatively with effort requirement. The response pattern was reversed in the pre-SMA and caudal ACC (Fig. 4c). However, these findings were not detectable after whole-brain TFCE-correction.

\subsubsection{Supplementary analyses}

3.2.4.1. Raw effort, physical effort subgroup. Findings generally overlapped with the main raw effort analysis. The analysis yielded one cluster in the bilateral precuneus and PCC and extending towards the right supramarginal gyrus, another in the bilateral SMA and dACC, and a 


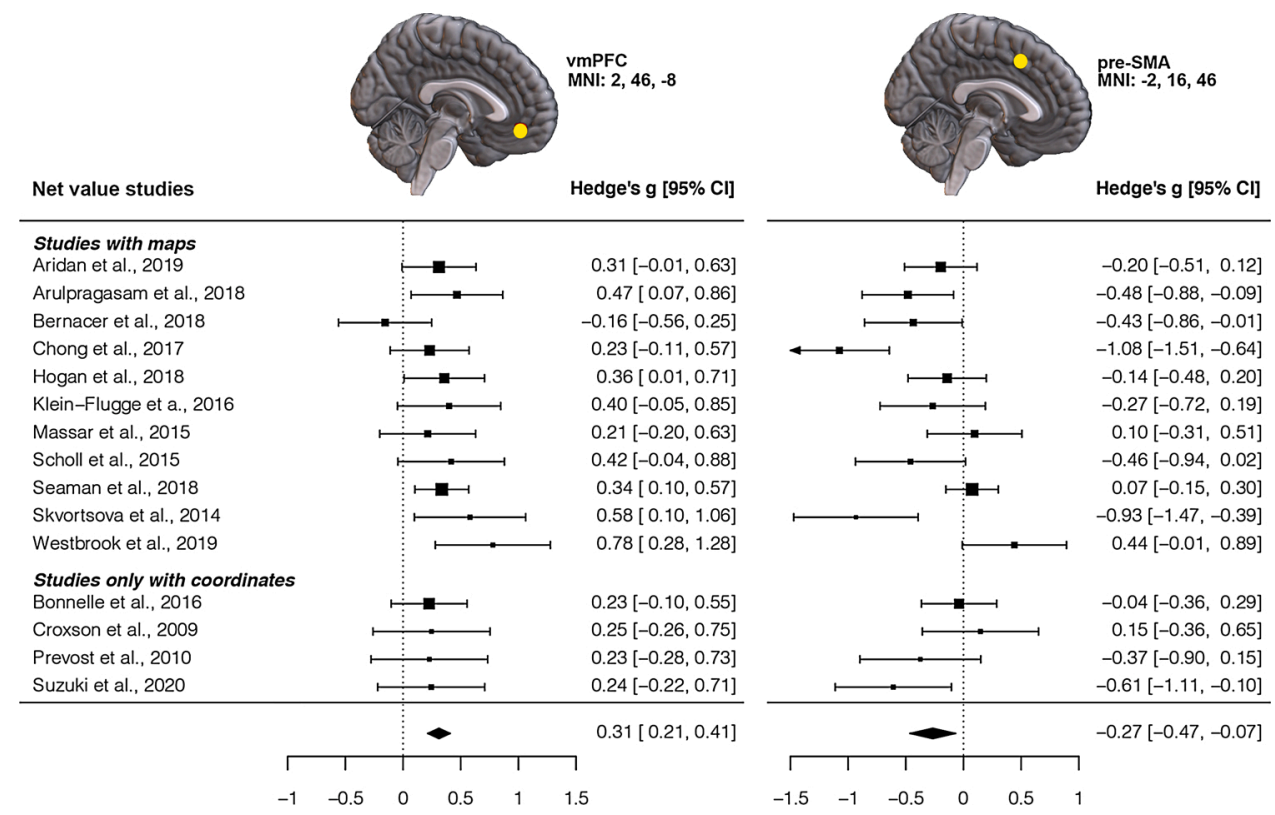

Fig. 3. Forest plot illustrating neural correlates of net value in the vmPFC and pre-SMA ROIs. The vmPFC is positively associated with net value (Hedge's $g=0.22$, 95 $\%$ CI $[0.22,0.44]$ ), whereas the pre-SMA showed a negative association (Hedge's $g=-0.28,95 \%$ CI $[-0.52,-0.03]$ ).

A

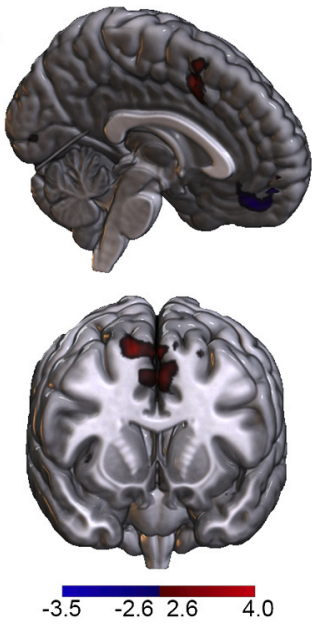

B

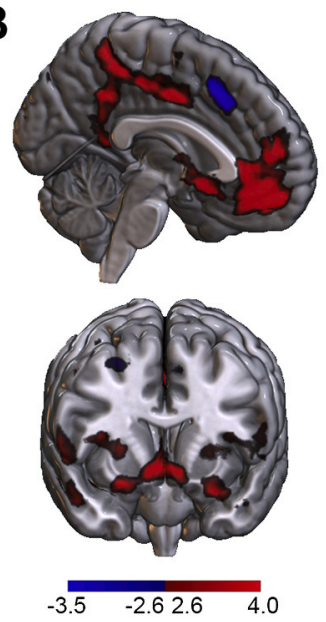

C

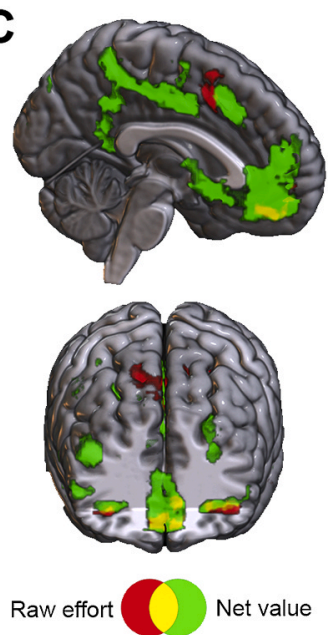

Fig. 4. Whole-brain meta-analytic results. A: neural activity related to pure effort cost representation; B: neural activity related to net value; and C: their conjunction based on absolute values. Display threshold: uncorrected $p<0.005$ at voxel level.

third, small cluster in the right frontal pole and dlPFC that were consistently positively associated with physical effort demands (see Table S2 and Fig. S14). However, unlike the original raw effort metaanalysis, negative association in the vmPFC not significant.

3.2.4.2. Net value, physical effort subgroup. Similar to the main net value analysis, BOLD activity in the mOFC, vmPFC, and rostral ACC, PCC and striatum was positively associated with the net value in studies measuring physical effort (see Table S3 and Fig. S15). Negative effects were also detected; however, they were associated with high heterogeneity (all $I^{2}>40 \%$ ).

3.2.4.3. Raw effort, online execution. Similar to the main prospective effort analysis, BOLD activity in the bilateral pre-SMA and ACC was positively associated with effort demand in studies requiring effort execution during the task (Table S4 and Fig. S16).

3.2.4.4. Other metrics of net value. To ensure that the results of the net value meta-analysis were not driven by choice difficulty, we reran our analysis excluding four experiments that used the value of two options as their net value metric (e.g. difference in SV of more vs less effortful option). Importantly, the vmPFC and bilateral VS remained to be the foci with highest effect sizes, and the whole-brain activation pattern was qualitatively similar (see Table S5 and Fig. S17), suggesting that our main findings were not influenced by the cognitive demands of comparing two options. Moreover, to ensure that our findings were robust when using a broader definition of net value, we also repeated our analysis including two additional studies that used reward and effort interactions as a measure of net value. Main foci and whole-brain activation patterns remained qualitatively similar to the initial net value meta-analysis (see Table S6 and Fig. S18). However, deactivations associated with net value were not detected in these supplementary analyses, suggesting that the deactivations in the SMA detected in the main meta-analysis were not robust.

3.2.4.5. Raw reward. The results showed that the activity of a large 
Table 3

Results of whole-brain analyses.

\begin{tabular}{|c|c|c|c|c|c|c|c|c|}
\hline Analysis & Cluster & Voxels & Peak MNI coordinates & BA & Regions & SDM-Z & $I^{2}($ in $\%)$ & Egger's $p$ \\
\hline \multirow[t]{20}{*}{ Net value } & \multirow[t]{12}{*}{$1^{*}$} & \multirow[t]{12}{*}{23,918} & $-4,52,-8$ & 10 & Left vmPFC & 7.05 & \multirow[t]{12}{*}{0.21} & \multirow[t]{12}{*}{0.70} \\
\hline & & & $2,52,-8$ & 11 & Right vmPFC & 6.47 & & \\
\hline & & & $8,10,-8$ & & Right NAc & 6.42 & & \\
\hline & & & $30,-6,-4$ & & Right putamen & 5.78 & & \\
\hline & & & $-32,-16,4$ & & Left putamen & 5.55 & & \\
\hline & & & $-22,-6,-14$ & 34 & Left amygdala & 5.40 & & \\
\hline & & & $24,0,-16$ & 34 & Right amygdala & 5.37 & & \\
\hline & & & $-50,-62,14$ & 37 & Left temporal gyrus & 5.34 & & \\
\hline & & & $-6,14,-8$ & & Left NAc & 5.26 & & \\
\hline & & & $-6,380$ & 11 & Left ACC & 5.17 & & \\
\hline & & & $-52,-50,2$ & 21 & Left middle temporal gyrus & 5.15 & & \\
\hline & & & $24,14,-16$ & 48 & Right insula & 5.13 & & \\
\hline & \multirow[t]{4}{*}{$2 *$} & \multirow[t]{4}{*}{3821} & $-14,-38,40$ & 23 & Left PCC & 5.59 & \multirow[t]{4}{*}{6.33} & \multirow[t]{4}{*}{0.44} \\
\hline & & & $-12,-40,44$ & & Left precuneus & 5.45 & & \\
\hline & & & $0,-8,42$ & 23 & Dorsal ACC & 5.00 & & \\
\hline & & & $-16,-34,40$ & & Left superior parietal gyrus & 4.88 & & \\
\hline & $3 *$ & 337 & $-26,28,38$ & 9 & Left dlPFC & 4.25 & 3.27 & 0.59 \\
\hline & 4 & 156 & $-8,16,52$ & 6 & Left SMA & -3.72 & 64.09 & 0.09 \\
\hline & 5 & 139 & $44,38,24$ & 8 & Right dlPFC & -4.26 & 50.05 & 0.19 \\
\hline & 6 & 26 & $16,20,58$ & 8 & Right superior frontal gyrus & -3.80 & 24.71 & 0.25 \\
\hline \multirow[t]{8}{*}{ Prospective effort } & $1 *$ & 112 & $8,16,64$ & 6 & Right SMA & 3.97 & 1.07 & 0.49 \\
\hline & 2 & 46 & $-8,8,52$ & 6 & Left SMA & 3.92 & 0.16 & 0.68 \\
\hline & 3 & 36 & $14,-66,38$ & 7 & Right precuneus & 3.62 & 59.40 & 0.11 \\
\hline & 4 & 23 & $-28,-6,50$ & 6 & Left middle frontal gyrus & 3.51 & 0.16 & 0.93 \\
\hline & 5 & 72 & $-8,56,-8$ & 11 & Left vmPFC & -4.26 & 5.90 & 0.63 \\
\hline & 6 & 67 & $-42,30,-14$ & 47 & Left OFC & -4.04 & $<0.01$ & 0.95 \\
\hline & 7 & 59 & $6,54,-14$ & 11 & Right vmPFC & -3.80 & 15.71 & 0.94 \\
\hline & 8 & 56 & $-56,-6,-18$ & 21 & Left middle temporal gyrus & -4.39 & 7.47 & 0.72 \\
\hline
\end{tabular}

All results survived a statistical threshold of voxel-level uncorrected $p<0.001$ and cluster size $>20$.

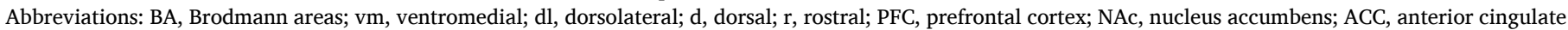
cortex; PCC, posterior cingulate cortex; SMA, supplementary motor area; OFC, orbitofrontal cortex.

* Regions survived a statistical threshold of TFCE-corrected $p<0.025$.

cluster, including the vmPFC, bilateral VS, DS, PCC, ACC, and some occipital regions, was positively associated with raw reward magnitude. These results largely overlapped with clusters identified in the net value analysis (Table S7 and Fig. S19).

\section{Discussion}

We conducted a series of combined coordinate- and image-based meta-analyses to examine the neural substrates of effort-based valuation. We first investigated neural activity related to raw effort and net value in seven a priori ROIs previously implicated in value-based decision-making. We found these regions could be broadly divided into two groups that exhibited distinct activity pattern during these two processes, with the vmPFC and pre-SMA as the central node of each. Specifically, the vmPFC scaled positively with net value but negatively with raw effort, whereas the pre-SMA displayed the opposite pattern. The exploratory whole-brain and conjunction analyses further corroborate the ROI analyses. These findings provide strong evidence for different, yet complementary, roles of the VmPFC and pre-SMA in the valuation of effort costs, and implicate these two regions as core components of a network that drives motivated behavior.

Our findings provide comprehensive evidence that effort-related net value integration is processed in a network centered around the vmPFC and VS. Accumulating evidence implicates the vmPFC as a general hub for value integration, as it has been identified to signal net value of rewards across different cost domains, such as risk and delay (Croxson et al., 2009; Hogan et al., 2019; Kable and Glimcher, 2007; Levy et al., 2010; Peters and Büchel, 2009; Schmidt et al., 2012; Westbrook et al., 2019). Additionally, the network including the vmPFC has been implicated in tracking net values across reward domains (i.e., primary, secondary, and aesthetic rewards), reward processing phases (Bartra et al., 2013; Clithero and Rangel, 2014; Levy and Glimcher, 2012; Sescousse et al., 2013), reward rates, and the value of current and previous offers (Mehta et al., 2019). These findings are therefore consistent with prominent neuroeconomic accounts which propose that the vmPFC represents the net value of an option in a 'common currency', in order to facilitate value comparison during decision making (Padoa-Schioppa, 2011; Rangel et al., 2008; Westbrook and Braver, 2015).

One would hypothesize that a region involved in representing net value would negatively scale with effort demands. Except for the vmPFC, our study did not find that other net-value-related regions, such as the VS, meet this requirement. These findings are at odds with previous reports that the VS activity is negatively modulated by effort costs in the presence of reward information (Westbrook et al., 2019). Moreover, dorsal parts of the striatum have also been found to track both effort costs (Burke et al., 2013; Guitart-Masip et al., 2012; Klein-Flügge et al., 2016; Kurniawan et al., 2013, 2010; Yang et al., 2016) and net value of prospective effortful rewards (Klein-Flügge et al., 2016; Seaman et al., 2018). However, our results implicate motor-related regions of the striatum, particularly the putamen, as signaling net value alone. One plausible explanation is that the striatum signals reward information during the evaluation of prospective effortful rewards (which we focused on in the current study) and encodes effort costs during the initiation of an effortful action (Suzuki et al., 2020). In line with this, studies that have experimentally isolated prospective effort and reward cues showed that the striatum was not activated by effort alone during the anticipation phase (Arulpragasam et al., 2018). However, future investigations that examine the role of the striatum during different time windows are needed to directly test this hypothesis.

The PCC also showed a reliable association with net value, but not effort requirement. Along with the vmPFC, the PCC is a critical node of the default mode network (Acikalin et al., 2017). It has also been considered as a key component of the valuation system in other cost domains (Bartra et al., 2013; Clithero and Rangel, 2014; Peters and Büchel, 2009). Its precise role in effort-based valuation remains largely unclear, but it has been implicated in monitoring temporal changes to the environment (Pearson et al., 2011) or integrating changes to the internal and external environment (Nakao et al., 2012). Moreover, 
previous studies have shown that the activity of the PCC was positively associated with the degree of uncertainty during value-based decision-making (McCoy and Platt, 2005). Taken together, the PCC may play a role in transmitting the background information to the vmPFC to guide the net value calculation, although it remains to be tested by studies that dissociate net value and these components.

Finally, both main and supplementary analyses consistently identified a variety of parietotemporal regions as scaling positively and uniquely with net value representations. While these regions (i.e. intraparietal lobule, intraparietal sulcus, temporal pole, etc.) have been previously implicated in SV encoding of effortful rewards (Chong et al., 2017; Massar et al., 2015), they also play a critical role in perceptual decision-making (Keuken et al., 2014), attention (Husain, 2019), risk weighting (Mohr et al., 2010), and decision difficulty (Westbrook et al., 2019). Their notable absence in reward processing (Keuken et al., 2014; Sescousse et al., 2013) may thus suggest that these parietotemporal regions are involved in high-level perceptual and cognitive functions associated with task demands as opposed to net value computation.

Previous studies have identified effort-related net value signals in other frontal regions, such as the pre-SMA and ACC, which suggests that these regions may be specifically relevant for effort-reward integration. In the current meta-analysis, however, we found that these regions - in particular, the pre-SMA and adjacent caudal ACC - all scaled positively with raw effort costs and, albeit less robustly, scaled negatively with net value. Such a pattern suggests that these regions are more likely to be involved in the processing of effort-related costs, rather than value integration per se. These findings align closely with a previous transcranial magnetic stimulation study, in which disruption of the SMA led to decreased effort perception (Zénon et al., 2015). The pre-SMA and dorsal ACC are also recruited to process other types of costs, such as risk (Mohr et al., 2010) and delay (Schüller et al., 2019). A plausible mechanism, therefore, is that these regions serve as a domain-general hub for cost encoding and transfer the cost information to the vmPFC for calculation of net value. Alternatively, neuroeconomic models of effort-based decision-making have posited that the ACC, in particular, is involved in good-to-action transformation (Padoa-Schioppa, 2011). Thus, another plausible mechanism is that the vmPFC computes and compares the net value of separate options and passes choice preference to action selection regions, such as the pre-SMA and ACC, for conversion to motor output.

Despite strong evidence about the involvement of the caudal ACC, which is close to the pre-SMA, in effort costs processing, it should be noted that the ACC, as a whole, is highly heterogeneous (Neubert et al., 2015; Yu et al., 2011). Indeed, the whole-brain results showed distinct response patterns across the ACC, in which the ventral part was mainly involved in net value computation, whereas the dorsal part in raw effort encoding. These findings suggest that subregions of the ACC could be linked to different aspects of the effort-related valuation, which may also partly explain the fact that some studies identified net value signals in the ACC (Klein-Flügge et al., 2016; Massar et al., 2015). Moreover, net-value-related activation may emerge in the dorsal ACC if it is highly correlated with other confounding variables, such as decision difficulty (Shenhav et al., 2013). It is particularly plausible for studies that have used the SV difference between two options as the net value parameter, as it often approximates decision difficulty (Klein-Flügge et al., 2016). Notably, studies that have experimentally isolated net value and decision difficulty showed that the cognitive control network, including the dorsal ACC and other frontoparietal regions, tracked the latter but not the former (Hogan et al., 2019; Westbrook et al., 2019).

The current study has some limitations. First, the sample size of the net value analysis is relatively small. Although the inclusion of statistical images partly offsets this issue, the number of included studies did not allow for us to perform meta-regressions, which would have provided more conclusive answers about the effects of potential moderators, such as effort type (i.e., physical vs. cognitive), parameter type (i.e., difference in SV vs. SV of one option), and effort execution requirement (i.e., real vs. hypothetical). These secondary analyses could be particularly relevant for understanding less consistent effects, such as the ones detected here in the pre-SMA ROI. Specifically, it is unclear if the high degree of heterogeneity in our net value effect size estimates in the preSMA ROI were due to differences in preparatory motor activity between tasks, selective networks engaged for cognitive vs. physical effort, or other unobserved factors, such as individual differences. Furthermore, sub-group meta-analyses investigating effects of different reward schedules (e.g., cumulative vs. random payout) were underpowered. Thus, we were unable to disambiguate between pure reward/effort integration and encoding of probabilistic features of the individual tasks. This is particularly important for effects observed in the PCC, OFC, and $\mathrm{mPFC}$, as these regions have been consistently involved in signaling prospective reward uncertainty (Bailey et al., 2016; Burke et al., 2013; Dreher, 2013; Peters and Büchel, 2009; Prévost et al., 2010). Given the sensitivity of effort-based decisions to both reward probability (Barch et al., 2014; Soder et al., 2020; Treadway et al., 2012) and opportunity costs (Otto and Daw, 2019), future research should directly explore the interaction between effort demand and other cost domains and/or task features. Second, the majority of the included studies focused on physical effort. These findings should be treated cautiously when generalizing to other formats of effort. Finally, the meta-analytic results reflected consistent regional neural correlates across studies. Although our study identified critical brain regions related to effort-related value integration or cost encoding, how these regions interact with each other to achieve the dynamic valuation process remains to be elucidated by studies using task-based connectivity technique (Hauser et al., 2017) or imaging methods with higher temporal resolution (e.g., magnetoencephalography).

In conclusion, this study is the first to use combined image- and coordinate-based meta-analyses to examine neural activity related to effort-related costs and net value. The results showed the pre-SMA is involved in cost representation of prospective effort independent of rewards. In contrast, the vmPFC and VS, which have been implicated in value integration in other cost domains, are also involved in effortreward integration. These findings further clarify the neural mechanisms underlying effort-related valuation and may provide candidate intervention targets for patients with decreased motivation to exert effort to obtain rewards.

\section{Declaration of Competing Interest}

The authors report no declarations of interest.

\section{Acknowledgements}

PL-G was supported by a fellowship from "la Caixa" Foundation (LCF/BQ/DI19/11730047). Y-WY was supported by the PhD fellowship of the Einstein Center for Neurosciences Berlin. TT-JC was supported by the Australian Research Council (DP 180102383 and DE 180100389). EM-H was supported by "la Caixa" Foundation (ID 100010434) and the European Union's Horizon 2020 research and innovation programme under the Marie Skłodowska-Curie grant agreement No 847648 (LCF/ BQ/PI20/11760001). JM-P was supported by grant PGC2018-098032B-I00 funded by MCIN/ AEI /10.13039/501100011033/ and by "ERDF A way of making Europe", and the ICREA Academia program. The authors would like to thank Nadav Aridan, Amanda Arulpragasam, Javier Bernacer, Michael Chee, Vikram Chib, Claudie Gaillard, Erica Grodin, Tobias Hauser, Masud Husain, Miriam Klein-Flügge, Irma Kurniawan, Stijn Massar, Il Ho Park, Mathias Pessiglione, Ceyda Sayalı, Jacqueline Scholl, Kendra Seaman, Vasilisa Skvortsova, Michael Treadway, and Andrew Westbrook for sharing whole-brain statistical maps or peak coordinates. 


\section{Appendix A. Supplementary data}

Supplementary material related to this article can be found, in the online version, at doi:https://doi.org/10.1016/j.neubiorev.2021.10 .024 .

\section{References}

Acikalin, M.Y., Gorgolewski, K.J., Poldrack, R.A., 2017. A coordinate-based metaanalysis of overlaps in regional specialization and functional connectivity across subjective value and default mode networks. Front. Neurosci. 11, 1. https://doi.org/ 10.3389/fnins.2017.00001.

Albajes-Eizagirre, A., Solanes, A., Vieta, E., Radua, J., 2019. Voxel-based meta-analysis via permutation of subject images (PSI): theory and implementation for SDM. Neuroimage 186, 174-184. https://doi.org/10.1016/j.neuroimage.2018.10.077.

Amiez, C., Sallet, J., Procyk, E., Petrides, M., 2012. Modulation of feedback related activity in the rostral anterior cingulate cortex during trial and error exploration. Neuroimage 63, 1078-1090. https://doi.org/10.1016/j.neuroimage.2012.06.023.

Aridan, N., Malecek, N.J., Poldrack, R.A., Schonberg, T., 2019. Neural correlates of effort-based valuation with prospective choices. Neuroimage 185, 446-454. https:// doi.org/10.1016/j.neuroimage.2018.10.051.

Arulpragasam, A.R., Cooper, J.A., Nuutinen, M.R., Treadway, M.T., 2018. Corticoinsular circuits encode subjective value expectation and violation for effortful goal-directed behavior. Proc. Natl. Acad. Sci. U. S. A. 115, E5233-E5242. https://doi.org/ 10.1073/pnas.1800444115.

Assadi, S.M., Yücel, M., Pantelis, C., 2009. Dopamine modulates neural networks involved in effort-based decision-making. Neurosci. Biobehav. Rev. 33, 383-393. https://doi.org/10.1016/j.neubiorev.2008.10.010.

Bailey, M.R., Simpson, E.H., Balsam, P.D., 2016. Neural substrates underlying effort, time, and risk-based decision making in motivated behavior. Neurobiol. Learn. Mem. 133, 233-256. https://doi.org/10.1016/J.NLM.2016.07.015.

Barch, D.M., Treadway, M.T., Schoen, N., 2014. Effort, anhedonia, and function in schizophrenia: reduced effort allocation predicts amotivation and functional impairment. J. Abnorm. Psychol. 123, 387-397. https://doi.org/10.1037/ a0036299.

Bartra, O., McGuire, J.T., Kable, J.W., 2013. The valuation system: a coordinate-based meta-analysis of BOLD fMRI experiments examining neural correlates of subjective value. Neuroimage 76, 412-427. https://doi.org/10.1016/j. neuroimage.2013.02.063.

Bernacer, J., Martinez-Valbuena, I., Martinez, M., Pujol, N., Luis, E., Ramirez-Castillo, D., Pastor, M.A., 2019. Neural correlates of effort-based behavioral inconsistency. Cortex 113, 96-110. https://doi.org/10.1016/j.cortex.2018.12.005.

Bonnelle, V., Manohar, S., Behrens, T., Husain, M., 2016. Individual differences in premotor brain systems underlie behavioral apathy. Cereb. Cortex 26, 807-819. https://doi.org/10.1093/cercor/bhv247.

Botvinick, M., Braver, T., 2015. Motivation and cognitive control: from behavior to neural mechanism. Annu. Rev. Psychol. 66, 83-113. https://doi.org/10.1146/ annurev-psych-010814-015044.

Botvinick, M.M., Carter, C.S., Braver, T.S., Barch, D.M., Cohen, J.D., 2001. Conflict monitoring and cognitive control. Psychol. Rev. 108, 624-652. https://doi.org/ 10.1037/0033-295X.108.3.624.

Burke, C.J., Brunger, C., Kahnt, T., Park, S.Q., Tobler, P.N., 2013. Neural integration of risk and effort costs by the frontal pole: only upon request. J. Neurosci. 33, 1706-1713. https://doi.org/10.1523/JNEUROSCI.3662-12.2013.

Camille, N., Tsuchida, A., Fellows, L.K., 2011. Double dissociation of stimulus-value and action-value learning in humans with orbitofrontal or anterior cingulate cortex damage. J. Neurosci. 31, 15048-15052. https://doi.org/10.1523/JNEUROSCI.3164 11.2011.

Cavanagh, J.F., Figueroa, C.M., Cohen, M.X., Frank, M.J., 2012. Frontal theta reflects uncertainty and unexpectedness during exploration and exploitation. Cereb. Cortex 22, 2575-2586. https://doi.org/10.1093/cercor/bhr332.

Chen, X., Voets, S., Jenkinson, N., Galea, J.M., 2020. Dopamine-dependent loss aversion during effort-based decision-making. J. Neurosci. 40, 661-670. https://doi.org/ 10.1523/JNEUROSCI.1760-19.2019.

Chong, T.T.J., 2018. Updating the role of dopamine in human motivation and apathy. Curr. Opin. Behav. Sci. 22, 35-41. https://doi.org/10.1016/j.cobeha.2017.12.010.

Chong, T.T.J., Husain, M., 2016. The role of dopamine in the pathophysiology and treatment of apathy. Progress in Brain Research. Elsevier B.V., pp. 389-426. https:// doi.org/10.1016/bs.pbr.2016.05.007

Chong, T.T.-J., Apps, M., Giehl, K., Sillence, A., Grima, L.L., Husain, M., 2017. Neurocomputational mechanisms underlying subjective valuation of effort costs. PLoS Biol. 15, e1002598 https://doi.org/10.1371/journal.pbio.1002598.

Clithero, J.A., Rangel, A., 2014. Informatic parcellation of the network involved in the computation of subjective value. Soc. Cogn. Affect. Neurosci. 9, 1289-1302. https:// doi.org/10.1093/scan/nst106.

Cowen, S.L., Davis, G.A., Nitz, D.A., 2012. Anterior cingulate neurons in the rat map anticipated effort and reward to their associated action sequences. J. Neurophysiol. 107, 2393-2407. https://doi.org/10.1152/jn.01012.2011.

Croxson, P.L., Walton, M.E., O’Reilly, J.X., Behrens, T.E.J., Rushworth, M.F.S., 2009. Effort-based cost-benefit valuation and the human brain. J. Neurosci. 29, 4531-4541. https://doi.org/10.1523/JNEUROSCI.4515-08.2009.

Cutler, Jo, Campbell-Meiklejohn, Daniel, 2019. A comparative fMRI meta-analysis of altruistic and strategic decisions to give. NeuroImage 184, 227-241. https://doi.org/ 10.1016/j.neuroimage.2018.09.009.
Daw, N.D., O’Doherty, J.P., Dayan, P., Seymour, B., Dolan, R.J., 2006. Cortical substrates for exploratory decisions in humans. Nature 441, 876-879. https://doi.org/ 10.1038/nature04766.

den Brok, M.G.H.E., van Dalen, J.W., van Gool, W.A., Moll van Charante, E.P., de Bie, R. M.A., Richard, E., 2015. Apathy in Parkinson's disease: a systematic review and meta-analysis. Mov. Disord. 30, 759-769. https://doi.org/10.1002/mds.26208.

Diekhof, E.K., Kaps, L., Falkai, P., Gruber, O., 2012. The role of the human ventral striatum and the medial orbitofrontal cortex in the representation of reward magnitude - an activation likelihood estimation meta-analysis of neuroimaging studies of passive reward expectancy and outcome processing. Neuropsychologia 50, 1252-1266. https://doi.org/10.1016/j.neuropsychologia.2012.02.007.

Dreher, J.-C., 2013. Neural coding of computational factors affecting decision making. Progress in Brain Research, pp. 289-320. https://doi.org/10.1016/B978-0-44462604-2.00016-2.

Egger, M., Smith, G.D., Schneider, M., Minder, C., 1997. Bias in meta-analysis detected by a simple, graphical test. Br. Med. J. 315, 629-634. https://doi.org/10.1136/ bmj.315.7109.629.

Gaillard, C., Guillod, M., Ernst, M., Torrisi, S., Federspiel, A., Schoebi, D., Recabarren, R. E., Ouyang, X., Mueller-Pfeiffer, C., Horsch, A., Homan, P., Wiest, R., Hasler, G., Martin-Soelch, C., 2019. Striatal responsiveness to reward under threat-of-shock and working memory load: a preliminary study. Brain Behav. 9. https://doi.org/ 10.1002/brb3.1397.

Grodin, E.N., Steckler, L.E., Momenan, R., 2016. Altered striatal response during effortbased valuation and motivation in alcohol-dependent individuals. Alcohol Alcohol. Suppl. 51, 638-646. https://doi.org/10.1093/alcalc/agw003.

Guitart-Masip, M., Chowdhury, R., Sharot, T., Dayan, P., Duzel, E., Dolan, R.J., 2012. Action controls dopaminergic enhancement of reward representations. Proc. Natl. Acad. Sci. U. S. A. 109.

Hartmann, M.N., Hager, O.M., Reimann, A.V., Chumbley, J.R., Kirschner, M., Seifritz, E., Tobler, P.N., Kaiser, S., 2015. Apathy but not diminished expression in schizophrenia is associated with discounting of monetary rewards by physical effort. Schizophr. Bull. 41, 503-512.

Hauser, T.U., Eldar, E., Dolan, R.J., 2017. Separate mesocortical and mesolimbic pathways encode effort and reward learning signals. Proc. Natl. Acad. Sci. 114, E7395-E7404. https://doi.org/10.1073/pnas.1705643114.

Hillman, K.L., Bilkey, D.K., 2010. Neurons in the rat anterior cingulate cortex dynamically encode cost-benefit in a spatial decision-making task. J. Neurosci. 30, 7705-7713. https://doi.org/10.1523/JNEUROSCI.1273-10.2010.

Hillman, K.L., Bilkey, D.K., 2012. Neural encoding of competitive effort in the anterior cingulate cortex. Nat. Neurosci. 15, 1290-1297. https://doi.org/10.1038/nn.3187.

Hogan, P.S., Galaro, J.K., Chib, V.S., 2017. Dissociable Roles of Ventromedial Prefrontal Cortex and Anterior Cingulate in Subjective Valuation of Prospective Effort. BioRxiv. https://doi.org/10.1101/079467.

Hogan, P.S., Galaro, J.K., Chib, V.S., 2019. Roles of ventromedial prefrontal cortex and anterior cingulate in subjective valuation of prospective effort. Cereb. Cortex 29, 4277-4290. https://doi.org/10.1093/cercor/bhy310.

Husain, M., 2019. Visual attention: what inattention reveals about the brain. Curr. Biol. 29, R262-R264. https://doi.org/10.1016/j.cub.2019.02.026.

Husain, M., Roiser, J.P., 2018. Neuroscience of apathy and anhedonia: a transdiagnostic approach. Nat. Rev. Neurosci. 19, 470-484. https://doi.org/10.1038/s41583-018 0029-9.

Kable, J.W., Glimcher, P.W., 2007. The neural correlates of subjective value during intertemporal choice. Nat. Neurosci. 10, 1625-1633. https://doi.org/10.1038/ nn2007.

Kahneman, D., Tversky, A., 1979. Prospect theory: an analysis of decision under risk. Econometrica 47, 263-291. https://doi.org/10.2307/1914185.

Keuken, M.C., Müller-Axt, C., Langner, R., Eickhoff, S.B., Forstmann, B.U., Neumann, J., 2014. Brain networks of perceptual decision-making: an fMRI ALE meta-analysis. Front. Hum. Neurosci. 8, 445. https://doi.org/10.3389/fnhum.2014.00445.

Klein-Flügge, M.C., Kennerley, S.W., Friston, K., Bestmann, S., 2016. Neural signatures of value comparison in human cingulate cortex during decisions requiring an effortreward trade-off. J. Neurosci. 36, 10002-10015. https://doi.org/10.1523/ JNEUROSCI.0292-16.2016.

Knutson, B., Greer, S.M., 2008. Anticipatory affect: neural correlates and consequences for choice. Philos. Trans. R. Soc. B Biol. Sci. 363, 3771-3786. https://doi.org/ 10.1098/rstb.2008.0155.

Knutson, B., Westdorp, A., Kaiser, E., Hommer, D., 2000. FMRI visualization of brain activity during a monetary incentive delay task. Neuroimage $12,20-27$. https://doi. org/10.1006/nimg.2000.0593.

Kolling, N., Behrens, T.E.J., Wittmann, M.K., Rushworth, M.F.S., 2016. Multiple signals in anterior cingulate cortex. Curr. Opin. Neurobiol. 37, 36-43. https://doi.org/ 10.1016/j.conb.2015,12.007.

Kool, W., McGuire, J.T., Rosen, Z.B., Botvinick, M.M., 2010. Decision making and the avoidance of cognitive demand. J. Exp. Psychol. Gen. 139, 665-682. https://doi. org/10.1037/a0020198.

Kouneiher, F., Charron, S., Koechlin, E., 2009. Motivation and cognitive control in the human prefrontal cortex. Nat. Neurosci. 12, 939-945. https://doi.org/10.1038/ nn. 2321.

Kurniawan, I.T., Seymour, B., Talmi, D., Yoshida, W., Chater, N., Dolan, R.J., 2010. Choosing to make an effort: the role of striatum in signaling physical effort of a chosen action. J. Neurophysiol. 104, 313-321. https://doi.org/10.1152/ jn.00027.2010.

Kurniawan, I.T., Guitart-Masip, M., Dolan, R.J., 2011. Dopamine and effort-based decision making. Front. Neurosci. 5, 81. https://doi.org/10.3389/fnins.2011.00081.

Kurniawan, I.T., Guitart-Masip, M., Dayan, P., Dolan, R.J., 2013. Effort and valuation in the brain: the effects of anticipation and execution. J. Neurosci. 33, 6160. 
Le Heron, C., Plant, O., Manohar, S., Ang, Y.-S., Jackson, M., Lennox, G., Hu, M.T., Husain, M., 2018. Distinct effects of apathy and dopamine on effort-based decisionmaking in Parkinson's disease. Brain 141, 1455-1469. https://doi.org/10.1093/ brain/awy110.

Levy, D.J., Glimcher, P.W., 2012. The root of all value: a neural common currency for choice. Curr. Opin. Neurobiol. 22, 1027-1038. https://doi.org/10.1016/j. conb.2012.06.001.

Levy, I., Snell, J., Nelson, A.J., Rustichini, A., Glimcher, P.W., 2010. Neural representation of subjective value under risk and ambiguity. J. Neurophysiol. 103, 1036-1047. https://doi.org/10.1152/jn.00853.2009.

Lopez-Gamundi, P., Wardle, M.C., 2018. The cognitive effort expenditure for rewards task (C-EEfRT): a novel measure of willingness to expend cognitive effort. Psychol. Assess. 30, 1237-1248. https://doi.org/10.1037/pas0000563.

Luijten, M., Schellekens, A.F., Kühn, S., Machielse, M.W.J., Sescousse, G., 2017. Disruption of reward processing in addiction: an image-based meta-analysis of functional magnetic resonance imaging studies. JAMA Psychiatry 74, 387-398. https://doi.org/10.1001/jamapsychiatry.2016.3084.

Massar, S.A.A., Libedinsky, C., Weiyan, C., Huettel, S.A., Chee, M.W.L., 2015. Separate and overlapping brain areas encode subjective value during delay and effort discounting. Neuroimage 120, 104-113. https://doi.org/10.1016/j. neuroimage.2015.06.080.

McCoy, A.N., Platt, M.L., 2005. Risk-sensitive neurons in macaque posterior cingulate cortex. Nat. Neurosci. 8, 1220-1227. https://doi.org/10.1038/nn1523.

Mehta, P.S., Tu, J.C., LoConte, G.A., Pesce, M.C., Hayden, B.Y., 2019. Ventromedial prefrontal cortex tracks multiple environmental variables during search. J. Neurosci. 39, 5336-5350. https://doi.org/10.1523/JNEUROSCI.2365-18.2019.

Mohr, P.N.C., Biele, G., Heekeren, H.R., 2010. Neural processing of risk. J. Neurosci. 30, 6613-6619. https://doi.org/10.1523/JNEUROSCI.0003-10.2010.

Mulert, C., Menzinger, E., Leicht, G., Pogarell, O., Hegerl, U., 2005. Evidence for a close relationship between conscious effort and anterior cingulate cortex activity. Int. J. Psychophysiol. 56, 65-80. https://doi.org/10.1016/j.ijpsycho.2004.10.002.

Müller, V.I., Cieslik, E.C., Laird, A.R., Fox, P.T., Radua, J., Mataix-Cols, D., Tench, C.R., Yarkoni, T., Nichols, T.E., Turkeltaub, P.E., Wager, T.D., Eickhoff, S.B., 2018. Ten simple rules for neuroimaging meta-analysis. Neurosci. Biobehav. Rev. 84, 151-161. https://doi.org/10.1016/j.neubiorev.2017.11.012.

Nagase, A.M., Onoda, K., Foo, J.C., Haji, T., Akaishi, R., Yamaguchi, S., Sakai, K., Morita, K., 2018. Neural mechanisms for adaptive learned avoidance of mental effort. J. Neurosci. 38, 2631-2651. https://doi.org/10.1523/JNEUROSCI.199517.2018.

Nakao, T., Ohira, H., Northoff, G., 2012. Distinction between externally vs. internally guided decision-making: operational differences, meta-analytical comparisons and their theoretical implications. Front. Neurosci. 6, 31. https://doi.org/10.3389/ fnins.2012.00031.

Neubert, F.X., Mars, R.B., Sallet, J., Rushworth, M.F.S., 2015. Connectivity reveals relationship of brain areas for reward-guided learning and decision making in human and monkey frontal cortex. Proc. Natl. Acad. Sci. U. S. A. 112, E2695-E2704. https://doi.org/10.1073/pnas.1410767112.

Otto, A., Daw, N., 2019. The opportunity cost of time modulates cognitive effort. Neuropsychologia 123. https://doi.org/10.1016/j.neuropsychologia.2018.05.006.

Padoa-Schioppa, C., 2011. Neurobiology of Economic Choice: A Good-Based Model. https://doi.org/10.1146/annurev-neuro-061010-113648.

Park, I.H., Lee, B.C., Kim, J.J., Kim Il, J., Koo, M.S., 2017. Effort-based reinforcement processing and functional connectivity underlying amotivation in medicated patients with depression and schizophrenia. J. Neurosci. 37, 4370-4380. https://doi.org/ 10.1523/JNEUROSCI.2524-16.2017.

Pearson, J.M., Heilbronner, S.R., Barack, D.L., Hayden, B.Y., Platt, M.L., 2011. Posterior cingulate cortex: adapting behavior to a changing world. Trends Cogn. Sci. 15, 143-151. https://doi.org/10.1016/j.tics.2011.02.002.

Peters, J., Büchel, C., 2009. Overlapping and distinct neural systems code for subjective value during intertemporal and risky decision making. J. Neurosci. 29, 15727-15734. https://doi.org/10.1523/JNEUROSCI.3489-09.2009.

Poldrack, R.A., Baker, C.I., Durnez, J., Gorgolewski, K.J., Matthews, P.M., Munafò, M.R., Nichols, T.E., Poline, J.B., Vul, E., Yarkoni, T., 2017. Scanning the horizon: towards transparent and reproducible neuroimaging research. Nat. Rev. Neurosci. 18, 115-126. https://doi.org/10.1038/nrn.2016.167.

Pooresmaeili, A., Wannig, A., Dolan, R.J., 2015. Receipt of reward leads to altered estimation of effort. Proc. Natl. Acad. Sci. U. S. A. 112, 13407-13410. https://doi. org/10.1073/pnas.1507527112.

Porat, O., Hassin-Baer, S., Cohen, O.S., Markus, A., Tomer, R., 2014. Asymmetric dopamine loss differentially affects effort to maximize gain or minimize loss. Cortex 51, 82-91. https://doi.org/10.1016/j.cortex.2013.10.004.

Prévost, C., Pessiglione, M., Météreau, E., Cléry-Melin, M.-L., Dreher, J.-C., 2010. Separate valuation subsystems for delay and effort decision costs. J. Neurosci. 30, 14080-14090. https://doi.org/10.1523/JNEUROSCI.2752-10.2010.

Radua, J., Mataix-Cols, D., Phillips, M.L., El-Hage, W., Kronhaus, D.M., Cardoner, N., Surguladze, S., 2012. A new meta-analytic method for neuroimaging studies that combines reported peak coordinates and statistical parametric maps. Eur. Psychiatry 27, 605-611. https://doi.org/10.1016/j.eurpsy.2011.04.001.

Radua, J., Pozo, N.O. del, Gómez, J., Guillen-Grima, F., Ortuño, F., 2014. Meta-analysis of functional neuroimaging studies indicates that an increase of cognitive difficulty during executive tasks engages brain regions associated with time perception. Neuropsychologia 58, 14-22. https://doi.org/10.1016/j. neuropsychologia.2014.03.016.

Rangel, A., Camerer, C., Montague, P.R., 2008. A framework for studying the neurobiology of value-based decision making. Nat. Rev. Neurosci. 9, 545-556. https://doi.org/10.1038/nrn2357.
Rudebeck, P.H., Walton, M.E., Smyth, A.N., Bannerman, D.M., Rushworth, M.F.S., 2006. Separate neural pathways process different decision costs. Nat. Neurosci. 9 , 1161-1168. https://doi.org/10.1038/nn1756.

Salamone, J.D., Correa, M., Farrar, A.M., Nunes, E.J., Pardo, M., 2009. Dopamine, behavioral economics, and effort. Front. Behav. Neurosci. 3, 13. https://doi.org/ 10.3389/neuro.08.013.2009.

Salamone, J.D., Correa, M., Yang, J.-H., Rotolo, R., Presby, R., 2018. Dopamine, effortbased choice, and behavioral economics: basic and translational research. Front. Behav. Neurosci. 12, 52. https://doi.org/10.3389/fnbeh.2018.00052.

Salimi-Khorshidi, G., Smith, S.M., Keltner, J.R., Wager, T.D., Nichols, T.E., 2009. Metaanalysis of neuroimaging data: a comparison of image-based and coordinate-based pooling of studies. Neuroimage 45, 810-823. https://doi.org/10.1016/j. neuroimage.2008.12.039.

Sayalı, C., Badre, D., 2019. Neural systems of cognitive demand avoidance. Neuropsychologia 123, 41-54. https://doi.org/10.1016/j. neuropsychologia.2018.06.016.

Schmidt, L., Lebreton, M., Cléry-Melin, M.-L., Daunizeau, J., Pessiglione, M., 2012. Neural mechanisms underlying motivation of mental versus physical effort. PLoS Biol. 10, e1001266.

Scholl, J., Kolling, N., Nelissen, N., Wittmann, M.K., Harmer, C.J., Rushworth, M.F.S., 2015. The good, the bad, and the irrelevant: neural mechanisms of learning real and hypothetical rewards and effort. J. Neurosci. 35, 11233-11251. https://doi.org/ 10.1523/JNEUROSCI.0396-15.2015.

Schüller, C.B., Kuhn, J., Jessen, F., Hu, X., 2019. Neuronal correlates of delay discounting in healthy subjects and its implication for addiction: an ALE meta-analysis study. Am. J. Drug Alcohol Abuse 45, 51-66. https://doi.org/10.1080/ 00952990.2018.1557675.

Seaman, K.L., Brooks, N., Karrer, T.M., Castrellon, J.J., Perkins, S.F., Dang, L.C., Hsu, M., Zald, D.H., Samanez-Larkin, G.R., 2018. Subjective value representations during effort, probability and time discounting across adulthood. Soc. Cogn. Affect. Neurosci. 13, 449-459. https://doi.org/10.1093/scan/nsy021.

Sescousse, G., Caldú, X., Segura, B., Dreher, J.C., 2013. Processing of primary and secondary rewards: a quantitative meta-analysis and review of human functional neuroimaging studies. Neurosci. Biobehav. Rev. 37, 681-696. https://doi.org/ 10.1016/j.neubiorev.2013.02.002.

Shenhav, A., Botvinick, M.M., Cohen, J.D., 2013. The expected value of control: an integrative theory of anterior cingulate cortex function. Neuron 79, 217-240. https://doi.org/10.1016/j.neuron.2013.07.007.

Skvortsova, V., Palminteri, S., Pessiglione, M., 2014. Learning to minimize efforts versus maximizing rewards: computational principles and neural correlates. J. Neurosci. 34, 15621-15630. https://doi.org/10.1523/JNEUROSCI.1350-14.2014.

Soder, H.E., Cooper, J.A., Lopez-Gamundi, P., Hoots, J.K., Nunez, C., Lawlor, V.M., Lane, S.D., Treadway, M.T., Wardle, M.C., 2020. Dose-response effects of damphetamine on effort-based decision-making and reinforcement learning. Neuropsychopharmacology 46, 1078-1085. https://doi.org/10.1038/s41386-0200779-8.

Stoppel, C.M., Boehler, C.N., Strumpf, H., Heinze, H.J., Hopf, J.M., Schoenfeld, M.A., 2011. Neural processing of reward magnitude under varying attentional demands. Brain Res. 1383, 218-229. https://doi.org/10.1016/j.brainres.2011.01.095.

Sutton, R.S., Barto, A.G., 1998. Reinforcement Learning: An Introduction. MIT Press, Cambridge, Mass.

Suzuki, S., Lawlor, V.M., Cooper, J.A., Arulpragasam, A.R., Treadway, M.T., 2020. Distinct Striatal Subregions and Corticostriatal Connectivity for Effort, Action and Reward. bioRxiv. https://doi.org/10.1101/2020.02.12.925313, 2020.02.12.925313.

Tanaka, S.C., Yamada, K., Yoneda, H., Ohtake, F., 2014. Neural mechanisms of gain-loss asymmetry in temporal discounting. J. Neurosci. 34, 5595-5602. https://doi.org/ 10.1523/JNEUROSCI.5169-12.2014.

Treadway, M.T., Memmer, M., Shelton, R.C., Zald, D.H., 2012. Neural mechanisms of effort-based decision-making in depressed patients. Biol. Psychiatry 71, 311s.

Vassena, E., Silvetti, M., Boehler, C.N., Achten, E., Fias, W., Verguts, T., 2014. Overlapping neural systems represent cognitive effort and reward anticipation. PLoS One 9, e91008. https://doi.org/10.1371/journal.pone.0091008.

Vassena, E., Deraeve, J., Alexander, W.H., 2017. Predicting motivation: computational models of PFC can explain neural coding of motivation and effort-based decisionmaking in health and disease. J. Cogn. Neurosci. 29, 1633-1645. https://doi.org/ 10.1162/jocn_a_01160.

Vassena, E., Deraeve, J., Alexander, W.H., 2020. Surprise, value and control in anterior cingulate cortex during speeded decision-making. Nat. Hum. Behav. 4, 412-422. https://doi.org/10.1038/s41562-019-0801-5.

Viechtbauer, W., 2010. Conducting meta-analyses in R with the metafor. J. Stat. Softw. 36, 1-48. https://doi.org/10.18637/jss.v036.i03.

Von Hippel, P.T., 2015. The heterogeneity statistic I2 can be biased in small metaanalyses. BMC Med. Res. Methodol. 15, 1-8. https://doi.org/10.1186/s12874-0150024-z.

Von Neumann, J., Morgenstern, O., 1990. Theory of Games and Economic Behavior. Princeton University Press, New York.

Walton, M.E., Bannerman, D.M., Alterescu, K., Rushworth, M.F.S., 2003. Functional specialization within medial frontal cortex of the anterior cingulate for evaluating effort-related decisions. J. Neurosci. 23, 6475-6479. https://doi.org/10.1523/ jneurosci.23-16-06475.2003.

Walton, M.E., Groves, J., Jennings, K.A., Croxson, P.L., Sharp, T., Rushworth, M.F.S., Bannerman, D.M., 2009. Comparing the role of the anterior cingulate cortex and 6hydroxydopamine nucleus accumbens lesions on operant effort-based decision making. Eur. J. Neurosci. 29, 1678-1691. https://doi.org/10.1111/j.14609568.2009.06726.x. 
Westbrook, A., Braver, T.S., 2015. Cognitive effort: a neuroeconomic approach. Cogn. Affect. Behav. Neurosci. 15, 395-415. https://doi.org/10.3758/s13415-015-0334-y.

Westbrook, A., Lamichhane, B., Braver, T., 2019. The subjective value of cognitive effort is encoded by a domain-general valuation network. J. Neurosci. 39, 3934-3947. https://doi.org/10.1523/JNEUROSCI.3071-18.2019.

Wilson, R.P., Colizzi, M., Bossong, M.G., Allen, P., Kempton, M., Bhattacharyya, S., 2018 The neural substrate of reward anticipation in health: a meta-analysis of fMRI findings in the monetary incentive delay task. Neuropsychol. Rev. 28, 496-506. https://doi.org/10.1007/s11065-018-9385-5.

Yang, X.H., Huang, J., Zhu, C.Y., Wang, Y.F., Cheung, E.F.C., Chan, R.C.K., Xie, G.R., 2014. Motivational deficits in effort-based decision making in individuals with subsyndromal depression, first-episode and remitted depression patients. Psychiatry Res. 220, 874-882. https://doi.org/10.1016/j.psychres.2014.08.056.
Yang, X.H., Huang, J., Lan, Y., Zhu, C.Y., Liu, X.Q., Wang, Y.F., Cheung, E.F.C., Xie, G.R., Chan, R.C.K., 2016. Diminished caudate and superior temporal gyrus responses to effort-based decision making in patients with first-episode major depressive disorder. Prog. Neuro-Psychopharmacology Biol. Psychiatry 64, 52-59. https://doi. org/10.1016/j.pnpbp.2015.07.006.

Yu, C., Zhou, Y., Liu, Y., Jiang, T., Dong, H., Zhang, Y., Walter, M., 2011. Functional segregation of the human cingulate cortex is confirmed by functional connectivity based neuroanatomical parcellation. Neuroimage 54, 2571-2581. https://doi.org/ 10.1016/j.neuroimage.2010.11.018.

Zénon, A., Sidibé, M., Olivier, E., 2015. Disrupting the supplementary motor area makes physical effort appear less effortful. J. Neurosci. 35, 8737-8744. https://doi.org/ 10.1523/JNEUROSCI.3789-14.2015. 